\title{
PROMOTING INCLUSIVE EDUCATION IN MONGOLIA
}

Karin Schelzig and Kirsty Newman

NO. 28

November 2020

\author{
ADB EAST ASIA \\ WORKING PAPER SERIES
}





\section{ADB East Asia Working Paper Series}

\section{Promoting Inclusive Education in Mongolia}

Karin Schelzig and Kirsty Newman

No. 28 | November 2020
Karin Schelzig is a principal social sector specialist in the Urban and Social Sectors Division of the East Asia Department, outposted to the People's Republic of China Resident Mission of ADB.

Kirsty Newman is a senior education specialist in the Education Sector Group of the Sustainable Development and Climate Change Department, on secondment to the Education Commission in the United Kingdom. 
(C) 2020 Asian Development Bank 6 ADB Avenue, Mandaluyong City, 1550 Metro Manila, Philippines

Tel +632 8632 4444; Fax +63286362444

www.adb.org

Some rights reserved. Published in 2020.

Printed in the Philippines

Publication Stock No. WPS200305-2

DOI: http://dx.doi.org/10.22617/WPS200305-2

The views expressed in this publication are those of the authors and do not necessarily reflect the views and policies of the Asian Development Bank (ADB) or its Board of Governors or the governments they represent.

ADB does not guarantee the accuracy of the data included in this publication and accepts no responsibility for any consequence of their use. The mention of specific companies or products of manufacturers does not imply that they are endorsed or recommended by ADB in preference to others of a similar nature that are not mentioned.

By making any designation of or reference to a particular territory or geographic area, or by using the term "country" in this document, $A D B$ does not intend to make any judgments as to the legal or other status of any territory or area.

This work is available under the Creative Commons Attribution 3.0 IGO license (CC BY 3.0 IGO)

https://creativecommons.org/licenses/by/3.0/igo/. By using the content of this publication, you agree to be bound by the terms of this license. For attribution, translations, adaptations, and permissions, please read the provisions and terms of use at https://www.adb.org/terms-use\#openaccess.

This CC license does not apply to non-ADB copyright materials in this publication. If the material is attributed to another source, please contact the copyright owner or publisher of that source for permission to reproduce it. $\mathrm{ADB}$ cannot be held liable for any claims that arise as a result of your use of the material.

Please contact pubsmarketing@adb.org if you have questions or comments with respect to content, or if you wish to obtain copyright permission for your intended use that does not fall within these terms, or for permission to use the ADB logo.

Corrigenda to ADB publications may be found at http://www.adb.org/publications/corrigenda.

Note:

In this publication, “\$” refers to United States dollars.

The ADB East Asia Working Paper Series is a forum for stimulating discussion and eliciting feedback on ongoing and recently completed research and policy studies undertaken by the East Asia Department of the Asian Development Bank (ADB) staff, consultants, or resource persons. The series deals with key economic and development problems, as well as conceptual, analytical, or methodological issues relating to project/program economic analysis, and statistical data and measurement. The series aims to enhance the knowledge on Asia's development and policy challenges; strengthen analytical rigor and quality of ADB's country partnership strategies, and its subregional and country operations; and improve the quality and availability of statistical data and development indicators for monitoring development effectiveness.

The ADB East Asia Working Paper Series is a quick-disseminating, informal publication whose titles could subsequently be revised for publication as articles in professional journals or chapters in books. The series is maintained by the East Asia Department. 


\section{CONTENTS}

TABLES, FIGURES, AND BOXES iv

FOREWORD AND ACKNOWLEDGMENTS vi

ABBREVIATIONS vii

$\begin{array}{lll}\text { ABSTRACT viii } & \text { vin }\end{array}$

1. INTRODUCTION: DISABILITY, POVERTY, AND EDUCATION IN MONGOLIA 1

1.1 Disability, Poverty, and Vulnerability in Mongolia 2

1.2 Access to Education: A Snapshot of the Data 3

1.3 A Brief Note on Methodology

2. TYPES OF DISABILITY, ACCESS TO EDUCATION, AND CAUSES OF DROPOUTS 9

2.1 Identifying Types of Disability 9

2.2 Access to Education $\quad 10$

3. THE LEGAL AND POLICY FRAMEWORK FOR INCLUSIVE EDUCATION IN 13 MONGOLIA

3.1 National Policies $\quad 13$

3.2 Selected Ministry of Education, Culture, Science and Sports Regulations and Policies 14

4. CONSTRUCTING MONGOLIAN INDICATORS OF INCLUSIVE EDUCATION 16

4.1 Inclusive Cultures 16

4.2 Inclusive Policies $\quad 20$

4.3 Inclusive Practices $\quad 22$

4.4 Inclusive Physical Environments $\quad 23$

5. CONCLUSIONS AND RECOMMENDATIONS FOR STRENGTHENING 31 INCLUSIVE EDUCATION IN MONGOLIA

$\begin{array}{ll}\text { REFERENCES } & 37\end{array}$ 


\section{TABLES, FIGURES, AND BOXES}

\section{TABLES}

$1 \quad$ Number of Children with Disabilities in Special Schools in Ulaanbaatar, 2017-2018 5

2 Washington Group Classification of Functional Ability 17

3 Number of Households and Children Surveyed 8

4 School Enrollment of Children with Functional Difficulties, Aged 6-17 11

5 Preschool Enrollment of Children with Functional Difficulties, Aged 2-5 12

6 Inclusive Culture Scores 17

7 Inclusive Policy Scores $\quad 20$

8 Inclusive Practice Scores $\quad 22$

9 Results of Observational Checklist Survey $\quad 24$

10 Stakeholder Collaboration for Inclusive Education 25

11 Matrix of Recommendations for Government and Development Partners 33

\section{FIGURES}

$1 \quad$ Number of Children with Disabilities in Kindergarten, 2012-2018 4

2 Number of Children with Disabilities in Regular Schools, 2012-2018 4

3 Number of Out-of-School Children, 2014-2018 6

4 Degree of Disability 10

5 Inclusive Culture in Schools $\quad 18$

6 Inclusive Culture in Kindergartens 19

7 Parents' Perceptions of Safety $\quad 20$

8 Inclusive Policy $\quad 21$

9 Inclusive Practice $\quad 23$

10 Problems with Outdoor Environments at Schools and Kindergartens 25

11 Difficulties with the Indoor Environments $\quad 27$

12 Accessibility of the Physical Environment at Schools 28

13 Activities to Improve the Accessibility of School and Kindergarten Environments as Reported by Parents $\quad 29$

14 Parents' Views on the Safety of the Indoor and Outdoor Environments 30

15 Teachers' Views on the Accessibility of Classrooms 30 


\section{BOXES}

1 Insufficient Support at School 13

2 How Do Teachers Work with Your Child? 20

3 Support for Special Needs at School 


\section{FOREWORD AND ACKNOWLEDGMENTS}

The Asian Development Bank (ADB) aims to advance social inclusion and human development, particularly among the poor and vulnerable groups, under the Strategy 2030 operational priority of addressing remaining poverty and reducing inequalities. Strategy 2030 includes persons with disabilities among the vulnerable groups. ADB supports the Sustainable Development Goals and global and national efforts to accelerate implementation of the Convention on the Rights of Persons with Disabilities and the Incheon Strategy to "Make the Right Real" for Persons with Disabilities in Asia and the Pacific. In November 2017, ADB approved its first stand-alone disability-inclusive development project-a $\$ 25$ million investment in Mongolia-to ensure better economic and educational opportunities and enhanced public service delivery for people with disabilities. ${ }^{a}$

In July 2018, ADB participated in the Global Disability Summit, signed the Global Disability Summit Charter for Change, and adopted several commitments to promote disability-inclusive development. Specific commitments to promote inclusive education included (i) reviewing the education portfolio to identify the gaps and potential to more effectively support inclusion of the most marginalized children in society, including out-of-school girls and boys with disabilities; and (ii) supporting innovations to expand the quality, scope, and range of accessible materials and teaching approaches for learners with disabilities, and make their physical environment more accessible via universal design.

This working paper is based on an original survey undertaken in 2019 by a team of experts from the Independent Research Institute of Mongolia (IRIM) in Ulaanbaatar, commissioned by ADB to assess barriers to education for children with functional difficulties in selected parts of the country. The IRIM team was led by Munkhbadar Judger and comprised Odgerel Dandii, Ariunbold Shagdar, Tamir Chultemsuren, Myagmarsaikhan Bazarsad, Byambasuren Dorjnyambuu, Lhagvatseren D, Jargalmaa Ganzorig, Bayartsetseg Khatanbaatar, and Ochbadral Altansukh.

The authors gratefully acknowledge funding for the survey from the Japan Fund for Poverty Reduction under ADB technical assistance 9216-MON Sustaining Access and Quality of Education During Economic Difficulties; and technical input to the survey design and methodology from ADB consultant Sulochini Pather, inclusive education specialist, Nazarbayev University, Kazakhstan. The paper also draws from the analytical work and consultations with inclusive education stakeholders in Mongolia, including disabled people's organizations and parents of children with disabilities, undertaken by ADB staff and consultants during the design of a grant to Mongolia for Support for Inclusive Education (approved July 2020).

This working paper benefited from insightful comments provided by ADB management and staff at a knowledge product dissemination seminar and by an external peer reviewer Joanna Rogers, disability inclusion specialist, Partnership for Every Child and Oxford Policy Management. Production assistance was provided by Monina Gamboa (copy editor), CodeMantra (layout), Corazon Desuasido (proofreader), with Francesca Cimacio providing overall coordination.

a ADB. 2017. Mongolia: Ensuring Inclusiveness and Service Delivery for Persons with Disabilities Project. Manila 


\section{ABBREVIATIONS}

$\begin{array}{ll}\text { ADB } & \text { Asian Development Bank } \\ \text { IDP } & \text { individual development plan } \\ \text { IRIM } & \text { Independent Research Institute of Mongolia } \\ \text { LLEC } & \text { Lifelong Education Center } \\ \text { MECSS } & \text { Ministry of Education, Culture, Science and Sports } \\ \text { MICS } & \text { Multiple Indicator Cluster Survey } \\ \text { MLSP } & \text { Ministry of Labor and Social Protection } \\ \text { MNUE } & \text { Mongolian National University of Education } \\ \text { NCLE } & \text { National Center for Lifelong Education } \\ \text { NSO } & \text { National Statistical Office } \\ \text { SDG } & \text { Sustainable Development Goal } \\ \text { TVET } & \text { technical and vocational education and training } \\ \text { UNESCO } & \text { United Nations Educational, Scientific and Cultural Organization } \\ \text { UNICEF } & \text { United Nations Children's Fund }\end{array}$




\begin{abstract}
Children with disabilities suffer disproportionately from the learning crisis. Although they represent only about $1.5 \%$ to $5 \%$ of the child population, they comprise more than half of out-of-school children globally. Inspired by a commitment that every child has the right to quality education, a growing global drive for inclusive education promotes an education system where children with disabilities receive an appropriate and high-quality education that is delivered alongside their peers. The global commitment to inclusive education is captured in the Sustainable Development Goal 4-ensuring inclusive and equitable education and promoting lifelong learning opportunities for all. This paper explores inclusive education for children with disabilities in Mongolia's mainstream education system, based on a 2019 survey of more than 5,000 households; interviews with teachers, school administrators, education ministry officials, and social workers; and visits to schools and kindergartens in four provinces and one district of the capital city. Mongolia has developed a strong legal and policy framework for inclusive education aligned with international best practice, but implementation and capacity are lagging. This is illustrated using four indicators of inclusive education: inclusive culture, inclusive policies, inclusive practices, and inclusive physical environments. The conclusion presents a matrix of recommendations for government and education sector development partners.
\end{abstract}




\section{INTRODUCTION: DISABILITY, POVERTY, AND EDUCATION IN MONGOLIA}

1. The world is facing a learning crisis that disproportionately affects children with disabilities. While there has been great progress in increasing access to education, children with disabilities are often the last group to achieve access. Of the 263 million out-of-school children globally, over half are children with disabilities, ${ }^{1}$ even though they represent only around $1.5 \%$ to $5 \%$ of the child population. ${ }^{2}$ Even those children with disabilities who are in school learn significantly less than other children. ${ }^{3}$ There are many reasons for these discrepancies in access and learning, including.

(i) discriminatory policy, which does not enable access to quality education for children with disabilities;

(ii) discrimination and bullying of children with disabilities, which can inhibit learning and discourage attendance;

(iii) lack of knowledge and/or capacity among teachers; and

(iv) low expectations about the capability of children with disabilities or stigma against their inclusion in schools. ${ }^{4}$

2. In response to this situation, and inspired by a commitment to the right of every child to quality education, a growing global drive for inclusive education promotes an education system where children with disabilities receive an appropriate and high-quality education that is delivered alongside their peers. Some are concerned that inclusion of children with disabilities in mainstream education could mean they do not receive specialized teaching, or that it could negatively impact the learning of other children in the classroom. However, a

Inclusive education enables all children to learn together with additional support for their individual needs. growing body of evidence demonstrates that well-implemented inclusive education is beneficial to both children with disabilities and children without disabilities who are taught alongside them (Kulbir and Alghaib 2019).

3. Defining inclusive education. In this paper, we broadly define inclusive education as enabling all children to learn together with additional support for their individual needs. ${ }^{5}$ According to General Comment 4 on the Convention on the Rights of Persons with Disabilities, ${ }^{6}$ states must ensure the realization of the right of persons with disabilities to education through an inclusive education system at all levels, including preschool, primary, secondary, and tertiary education; vocational training and lifelong learning; and extracurricular and social activities. This should be for all students, including persons with disabilities, without discrimination and on an equal basis with others. Per para. 10 of General Comment No. 4, inclusive education is to be understood as follows:

(i) A fundamental human right of all learners. Notably, education is the right of the individual learner and not, in the case of children, the right of a parent or caregiver. Parental responsibilities in this regard are subordinate to the rights of the child;

\footnotetext{
Education Commission. 2017. The Learning Generation. New York: The Education Commission.

World Health Organization and World Bank. 2011. World Report on Disability. Malta.

3 Male, C. and Q. Wodon. 2017. The Price of Exclusion: Disability and Education. Disability Gaps in Educational Attainment and Literacy. Washington DC: Global Partnership for Education and The World Bank.

4 Kulbir Singh, R. and O. Abu Alghaib. 2019. Every Learner Matters: Unpacking the Learning Crisis for Children With Disabilities. Washington, DC: World Bank Group.

5 Save the Children. 2016. Inclusive Education: What, Why, and How: A Handbook for Program Implementers. Stockholm.

6 United Nations. 2016. Committee on the Rights of Persons with Disabilities General Comment No. 4 (2016) on the Right to Inclusive Education. CPRD/C/GC 4. Geneva.
} 
(ii) A principle that values the well-being of all students, respects their inherent dignity and autonomy, and acknowledges individuals' requirements and their ability to effectively be included in and contribute to society;

(iii) A means of realizing other human rights. It is the primary means by which persons with disabilities can lift themselves out of poverty, obtain the means to participate fully in their communities, and be safeguarded from exploitation. It is also the primary means of achieving inclusive societies; and

(iii) The result of a process of continuing and proactive commitment to eliminating barriers impeding the right to education, together with changes to culture, policy, and practice of regular schools to accommodate and effectively include all students.

4. The goal is for the whole education system to facilitate learning environments where teachers and learners embrace and welcome both the challenges and the benefits of diversity. Inclusive education fosters productive learning environments while meeting individual needs, giving every student an opportunity to succeed. The global commitment to inclusive education is also captured in the Sustainable Development Goal (SDG) 4 of ensuring inclusive and equitable education and promoting lifelong learning opportunities for all.

\subsection{Disability, Poverty, and Vulnerability in Mongolia}

5. Estimating the incidence of disability. According to Mongolia's National Program for the Rights, Protection, and Participation of Persons with Disabilities, there were nearly 101,000 Mongolians living with disabilities in 2017. 'This number may be an underestimation since it represents just over $3 \%$ of the population of 3.24 million. The prevalence of children with disabilities may also be underestimated: the country's social welfare database included 11,244 children with disabilities in 2018, but eligibility for social welfare benefits requires a formal diagnosis, and not all children with functional difficulties are formally diagnosed. ${ }^{8}$ In our survey, only one in five of the nearly 700 children with functional difficulties had a formal diagnosis (discussed in Chapter 2). The World Health Organization assesses that about 15\% of the world's population and $1.5 \%-5 \%$ of the world's child population live with some form of disability (WHO and World Bank 2011). This global average incidence would imply more than 485,000 adults and up to 59,150 children with disabilities in Mongolia. The National Statistical Office (NSO) Household Socio-Economic Survey, the Living Standards Assessment Database, and the Multiple Cluster Indicator Survey (MICS) also provide important prevalence and other data on adults and children with disabilities.

6. Persons with disabilities are more likely to be poor than the rest of the population. A 2016 study that supported the design of ADB's first-ever disability inclusion project (details in the foreword) found that the poverty rate among Mongolian households with one or more persons with disabilities is more than double that of households with none. ${ }^{9}$ Persons with disabilities are more likely to be poor because of physical, financial, and cultural barriers to education and skills development, and consequently, to good jobs and other forms of social inclusion. Among Mongolian persons with disabilities of working age, fewer than one in five (19\%) are employed, in stark contrast to working-age people without disabilities, among whom nearly two-thirds (64\%) are employed (ADB 2019b).

7. Mongolia's 2016 Law on the Rights of Persons with Disabilities enshrines the right to education and specifies the duty of schools to adapt to the needs of children with disabilities, of parents to enroll their

Government of Mongolia. 2017. National Program for the Rights, Participation, and Protection of Persons with Disabilities, 2018-2022. Ulaanbaatar.

8 ADB. 2019c. Mongolia's Social Welfare System: Expenditure Allocation and Beneficiary Profile. Consultant's report. Manila (TA 8845-MON).

9 ADB. 2019b. Living with Disability in Mongolia: Progress Toward Inclusion. Manila. 
children in school, and of social workers to provide information and support. ${ }^{10}$ However, boys and girls with disabilities remain excluded from quality mainstream education, and low educational attainment is a major source of vulnerability. Overall, one out of every five Mongolian persons with disabilities has not completed any level of education, compared to fewer than $4 \%$ of the rest of the population. ${ }^{11}$

8. According to United Nations Children's Fund (UNICEF) data, fewer than half of children with disabilities (44\%) were enrolled in mainstream schools in 2010.12 While this proportion has improved in the intervening decade, it remains lower for children with disabilities than for children without disabilities, particularly in remote rural areas. This is reflected in the dramatic disparities in literacy: among children with disabilities aged 6-18 in 2014, almost half were unable to read, as compared to $4 \%$ of those without disabilities. Nearly two-thirds of children with disabilities aged 3-5 (64\%) are not attending kindergarten, versus about one-third of children of the same age without disabilities (32\%) (ADB 2019a). There are also gender disparities in education-boys' enrollment as a share of the total drops in higher grades, both in the general population and among children with disabilities.

9. Expanding the meaning of disability. With Mongolia's transition from a socialist, centralized system to a democratic, free market economy starting in the mid-1990s, the country also experienced education reforms and a change in societal attitudes toward children from marginalized groups and with functional difficulties. Still, recent surveys reveal that Mongolia's teachers perceive inclusive education mainly as the inclusion of children with physical disabilities in mainstream schools. ${ }^{13}$ This narrow perception may have been influenced by the former Soviet Union-era special education system where so-called "defectologists" (special education teachers) were trained in tiflopedagogy (teaching the blind), surdopedagogy (teaching the deaf), and oligophrenopedagogy (teaching children with cognitive disabilities) (Save the Children 2018). Teachers' perceptions may also be influenced by the Mongolian language terminology, where the phrase for children with disabilities directly translates to children with development problems or children with physical impairments. Our survey applied a broader meaning, using the Washington Group/UNICEF child functioning module to classify children's functional difficulties (see the methodology discussion on page 7).

\subsection{Access to Education: A Snapshot of the Data}

10. Preprimary education. Mongolia had 1,435 preprimary institutions (kindergartens) as of school year 2018-2019, with more than 261,350 children enrolled and a net enrollment rate of about $75 \%$. The vast majority of kindergartens (nearly 93\%) are regular (or mainstream), and just over 6\% are ger kindergartens in remote areas. There are four "special" kindergartens for children with disabilities and five nursing kindergartens for children with severe disabilities in Ulaanbaatar. Among all kindergarten children, only 1,087 or $0.4 \%$ are children with disabilities. Figure 1 shows that the number of kindergartens has been steadily increasing year by year, but there was a sharp decline in the number of children with disabilities enrolled from 2017 to 2018.

10 Article 4.1.1 of the 2016 Law of Mongolia on the Rights of Persons with Disabilities defines persons with disabilities as those who have long-term physical, mental, intellectual, or sensory impairments, which, in interaction with various barriers, may hinder their full and effective participation in society equally with others. This definition is aligned with the United Nations Convention on the Rights of Persons with Disabilities, which recognizes that disability is not only a health condition, but also a result of social and environmental barriers.

11 ADB. 2019a. Integrating Persons with Disabilities into Mongolia's Society. Observations and Suggestions 2019-02. Manila.

12 UNICEF. 2016b. UNICEF Mongolia Country Programme Document 2017-2021. Ulaanbaatar.

13 Save the Children. 2018. Needs Assessment for Promoting Inclusive Education for Every Last Child in Mongolia. Ulaanbaatar: International Research Institute of Mongolia. 
Figure 1: Number of Children with Disabilities in Kindergarten, 2012-2018

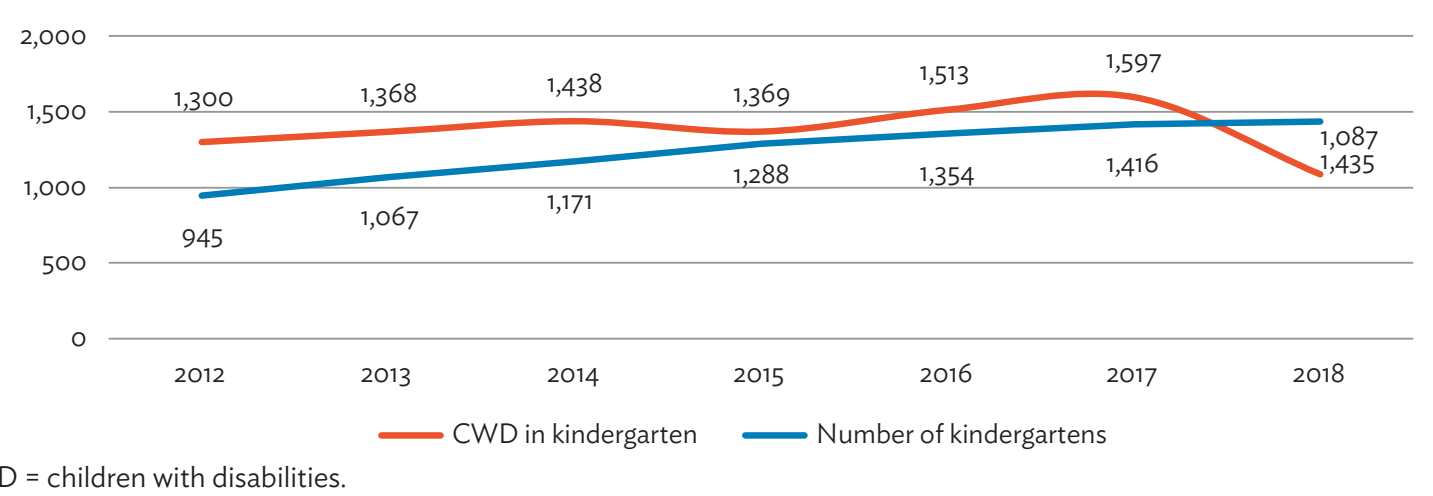

Source: Ministry of Education, Culture, Science and Sports education statistics, 2019.

11. Several factors may explain the relatively low number of children with disabilities in preprimary schools. By law, up to two children with mild disabilities may be enrolled in regular classrooms. However, formal identification and diagnosis of disabilities is weak, and due to the lack of proper assessments, kindergarten teachers must evaluate the level of a child's disability themselves. Teachers may discriminate against children, depending on the type and degree of disability. With a very high average number of children per kindergarten classroom at 35-40, teachers may be reluctant to enroll children with disabilities in a regular classroom due to heavy workloads and a lack of assistant teachers or other support.

12. As only health institutions screen and detect disabilities in the early stages of childhood, early identification of other developmental issues-such as attention deficit, behavioral, cognitive, and learning difficulties - is limited. Many children with functional difficulties go undiagnosed, which may also explain the low numbers of children with disabilities in early childhood education.

13. Mainstream basic education. In 2016, the Ministry of Education, Culture, Science and Sports (MECSS) ${ }^{14}$ (which became the Ministry of Education and Science in July 2020) introduced an education sector information system (www.esis.edu.mn) comprising basic statistics on students, teachers, administrators, activities, learning environment, textbooks, and finances. District and provincial

Figure 2: Number of Children with Disabilities in Regular Schools, 2012-2018

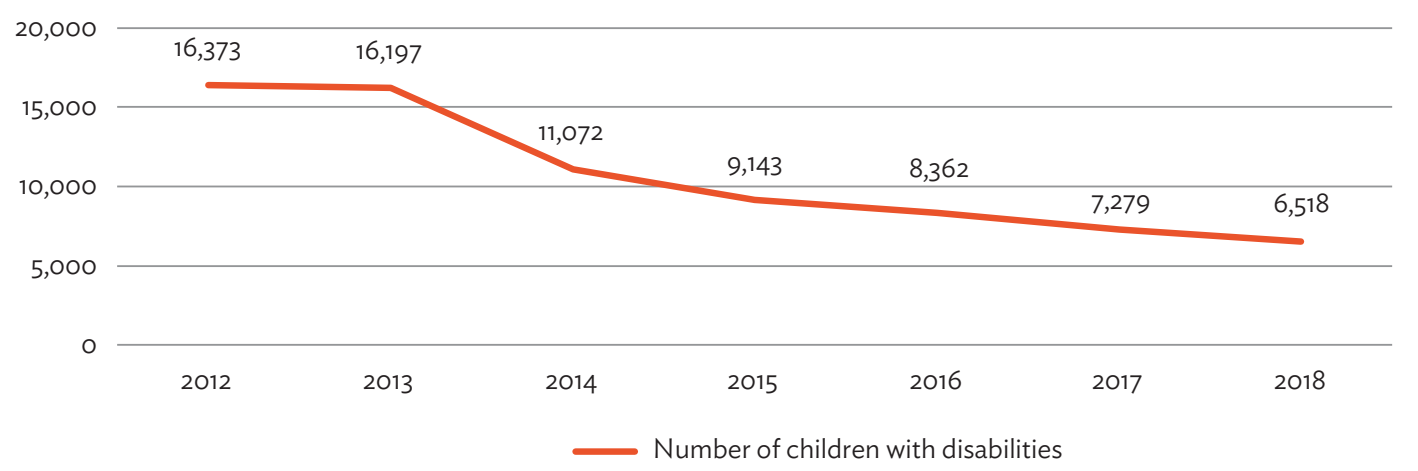

Source: Ministry of Education, Culture, Science and Sports education statistics, 2019.

14 In July 2020, the Ministry of Education, Culture, Science and Sports became the Ministry of Education and Science. MECSS is used throughout this report. 
education specialists register the information on children with disabilities. In the last 5 years, the number of children with disabilities dramatically decreased (Figure 2), but specialists cannot explain this, because the methodology for identification is not reliable.

14. Teachers typically learn about children with disabilities through a doctor's diagnosis and/or notification from parents, but some disabilities such as autism spectrum disorder (ASD), attention deficit hyperactivity disorder (ADHD), and learning difficulties are diagnosed by teachers based on their personal understanding. In a Save the Children 2018 survey on inclusive education, all mainstream school managers pointed out that teachers consider all children with poor results as having learning difficulties and those who are hyperactive as having ADHD (Save the Children 2018). This is due to the absence of a unified definition and classification of children with disabilities in the education system.

15. The 2016 Law of Mongolia on the Rights of Persons with Disabilities refers to teacher training in article 16.2, requiring teachers or social workers working at all educational institutions to have knowledge and methodologies for working with children with disabilities. However, there is a large gap between the policy and the reality of school practices. The Save the Children needs assessment survey confirmed that $88 \%$ of teachers at regular schools were not adequately prepared to work with children with disabilities (Save the Children 2018). Chapter 4 explores our survey results on the gaps between policy and practice.

16. Special schools. There are six special schools in Ulaanbaatar, and one in Darkhan aimag. Among the special schools in the capital city (Table 1), one is for children with visual impairment, one specializes in hearing impairment, and four schools enroll children with intellectual disabilities. There were 1,637 children in these schools in the 2017-2018 school year. The capacity to support different disabilities differs from school to school: schools \#25 and \#63 are more oriented toward children with severe disabilities, whereas school \#55 has provisions for occupational training for children with "psychological delay".

Table 1: Number of Children with Disabilities in Special Schools in Ulaanbaatar, 2017-2018

\begin{tabular}{llcccccr}
\hline $\begin{array}{l}\text { Special } \\
\text { Schools }\end{array}$ & Classification & Total & Girls & Boys & Elementary & \multicolumn{2}{c}{$\begin{array}{c}\text { Seconior } \\
\text { High School }\end{array}$} \\
\hline School \#55 & Intellectual & 478 & 200 & 278 & 247 & 182 & 49 \\
\hline School \#63 & Intellectual & 233 & 97 & 136 & 116 & 117 & $\ldots$ \\
\hline School \#29 & Deaf & 315 & 140 & 175 & 133 & 120 & 62 \\
\hline School \#116 & Blind & 104 & 42 & 62 & 65 & 34 & 5 \\
\hline School \#25 & Intellectual & 208 & 83 & 125 & 106 & 103 & $\ldots$ \\
\hline School \#70 & Intellectual & 299 & 113 & 186 & 189 & 110 & $\ldots$ \\
\hline Total & & 1,637 & 675 & 962 & 856 & 665 & 116 \\
\hline
\end{tabular}

(...) = no date available.

Source: Independent Research Institute of Mongolia. 2019. Support for Inclusive Education. Technical assistance consultant's report prepared for the Asian Development Bank. Manila.

17. Lifelong Education Centers. These Lifelong Education Centers (LLECs) are run by the National Center for Lifelong Education (NCLE), a government agency with several goals: reducing the number of out-of-school children; providing education and literacy for vulnerable children whose rights to education are restricted; providing primary, basic, and secondary education programs for unemployed and low-income people; delivering vocational orientation and training while building capacity of LLEC teachers; and providing education programs in life sciences, ecology, health, and civil and sustainable development. 
18. In 2019, 355 LLECs operated across the country's 21 aimags and nine districts of Ulaanbaatar, offering lifelong education and equivalent alternative programs. Lifelong education programs include life skills, family education, civic education, ethical or moral education, aesthetic education, and scientific education. Equivalency programs include primary, basic, and secondary education, and life skills-based literacy programs. The content of LLEC primary education comprises the four subjects of Mongolian language; mathematics; drawing, art, and technology; and nature, human beings, and health.

19. Procedures for the enrollment of children with disabilities vary from one LLEC to another, as do teacher attitudes-many teachers accept children with disabilities only for the equivalent alternative programs. In the 2018-2019 school year, the 355 LLECs enrolled 7,296 children among which 933 (12.8\%) were children with disabilities (42.1\% at the primary level, $47.2 \%$ in junior secondary, and $10.7 \%$ in high school). LLECs in eight aimags also offer home-based training for children with severe disabilities. During 2018-2019, 72 boys and 59 girls with severe disabilities received home-based training.

20. Out-of-school children. Article 20.2.8 of the Law on Primary and Secondary Education states that school and kindergarten directors are obliged to enroll all children in their enrollment zones and provide them with basic education. Enrollment zones are set by the Ulaanbaatar and aimag education departments. School and kindergarten dropout records are kept at the khoroo level, but the information is not regularly updated. This hinders obtaining an accurate picture of school dropouts. According to NSO data from the 2018-2019 school year, only 759 school-aged children were not in school (Figure 3). Nearly $70 \%$ of these children never attended school, while the rest are considered dropouts. However, a 2019 NCLE survey in two provinces and three districts of Ulaanbaatar found a significantly higher number of children who have dropped out of school than reported by the NSO, and dropouts were higher for children at the primary level between 6 and 10 years of age..$^{15}$

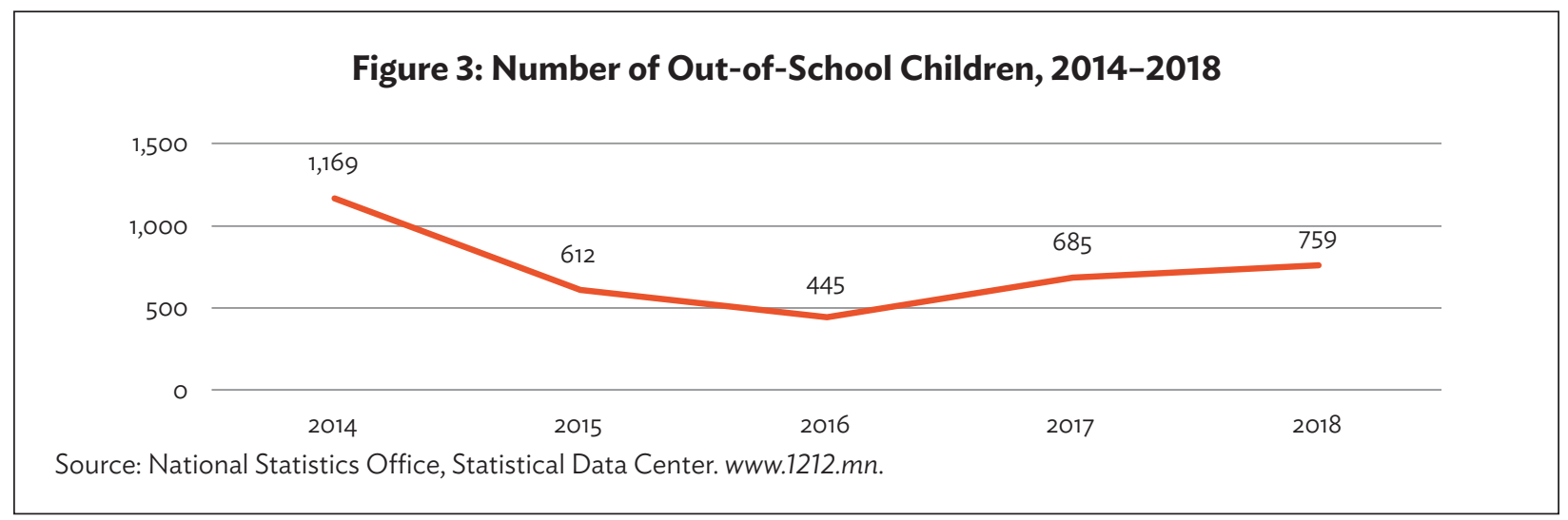

21. According to the National Human Rights Commission of Mongolia, the main reasons children drop out of school are disabilities and health conditions and poverty, or their family's socioeconomic situation. ${ }^{16}$ The 2018 Save the Children survey revealed that the main reasons children with special needs (including children with disabilities) drop out are (i) the family's financial situation and/or poor parental care; (ii) insufficient and inadequate school infrastructure, classrooms, and training materials; and (iii) health conditions arising from disabilities (Save the Children 2018). Children with severe disabilities often need permanent care. According to the NCLE 2019 survey, there are 3,372 children with severe disabilities aged 6-18. Recalling the discussion above, only 131 of them, or 3.8\%, receive LLEC home-based training.

15 NCLE. 2019. Screening School-Aged Children Out of School. National Commission for Lifelong Education Survey Report. Ulaanbaatar.

16 National Human Rights Commission. 2018. Implementation of the Right to Education for Children with Disabilities and Their Dropout. Unpublished. 


\subsection{A Brief Note on Methodology}

22. This working paper presents data from an ADB survey and qualitative research in selected provinces of Mongolia, undertaken in 2019 by the Independent Research Institute of Mongolia (IRIM, Ulaanbaatar). ADB commissioned the study to help identify the barriers to education for children with disabilities in selected parts of the country, as part of the design process of a new grant to support inclusive education. The study was based on the concepts in the Law on the Rights of Persons with Disabilities and used both quantitative and qualitative methods, including an extensive household survey; in-depth interviews; and focus group discussions with parents, teachers, school administrators, and social workers. The survey team collected quantitative data from 5,328 households in Darkhan, Dornod, Dundgovi, and Khuvsgul provinces, and from the Songino-Khairkhan district of Ulaanbaatar. Except for Khuvsgul, these are the ADB grant's focus areas, chosen in consultation with the MECSS. IRIM and $A D B$ validated the survey results and recommendations with civil society groups, including disabled people's organizations, in a September 2019 forum in Ulaanbaatar. Several additional consultations with civil society organizations and disabled people's organizations informed the design of the new grant.

23. The ADB survey used the Washington Group/UNICEF child functioning module to screen children for functional difficulties. ${ }^{17}$ Functional difficulties refer to challenges with key skills that are required for day-to-day activities that can directly affect the development of children when they are in a non-accessible environment. The module examines a range of functional standards with eight domains for children aged 2-5 and 12 domains for children aged 6-17 (Table 2). The survey screened 9,555 children aged 2-17 from the 5,328 households (Table 7).

Table 2: Washington Group Classification of Functional Ability

\begin{tabular}{ll}
\hline \multicolumn{1}{c}{ Children Aged 2-5 } & \multicolumn{1}{c}{ Children Aged 6-17 } \\
\hline Seeing & Seeing \\
\hline Hearing & Hearing \\
\hline Walking & Walking \\
\hline Fine motor skills & Self-care \\
\hline Communication and/or comprehension & Communication and/or comprehension \\
\hline Learning & Learning \\
\hline Playing & Remembering \\
\hline Controlling behavior & Focusing attention and concentrating \\
& Coping with change \\
& Controlling behavior \\
& Relationships \\
& Emotions (anxiety and depression) \\
\hline
\end{tabular}

Source: UNICEF. 2016a. Child Functioning Module Questionnaires. New York.

UNICEF. 2016a. Child Functioning Module Questionnaires. New York.

24. The screening identified 874 children or $9 \%$ as having functional difficulties: 106 children were aged $2-5$ and 768 children were aged $6-17$. In terms of location, the percentage was highest in Ulaanbaatar (12.9\%) and lowest in Dornod (6.3\%). The survey team found a significantly higher proportion of children with a functional difficulty compared to the results of the NSO 2018 MICS. NSO's results are

17 The Washington Group/UNICEF Module on Child Functioning, finalized in 2016, covers children between 2 and 17 years of age and assesses functional difficulties in different domains including hearing, vision, communication and/or comprehension, learning, mobility, and emotions. To better reflect the degree of functional difficulty, each area is assessed against a rating scale. The purpose is to identify the subpopulation of children who are at greater risk than other children of the same age or who are experiencing limited participation in an unaccommodating environment. Information obtained from https://data. unicef.org/resources/module-child-functioning/. 
4 percentage points lower because of methodological differences: NSO applied a narrower definition of functional difficulty. ${ }^{18}$

Table 3: Number of Households and Children Surveyed

\begin{tabular}{|c|c|c|c|c|c|c|}
\hline & \multirow[b]{2}{*}{ Total } & \multicolumn{5}{|c|}{ Location } \\
\hline & & Dornod & Darkhan & Dundgovi & Khuvsgul & Ulaanbaata \\
\hline \multicolumn{7}{|l|}{ Households } \\
\hline $\begin{array}{l}\text { Households } \\
\text { eligible for the } \\
\text { interview }\end{array}$ & 7,563 & 2,141 & 2,272 & 965 & 179 & 2,006 \\
\hline $\begin{array}{l}\text { Interviewed } \\
\text { households }\end{array}$ & 5,296 & 1,518 & 1,437 & 615 & 162 & 1,564 \\
\hline $\begin{array}{l}\text { Response rate, } \\
\text { percentage }\end{array}$ & 70.4 & 66.3 & 64.9 & 65.7 & 95.0 & 81.3 \\
\hline \multicolumn{7}{|l|}{$\begin{array}{l}\text { Number of } \\
\text { children }\end{array}$} \\
\hline Interviewed & 9,555 & 2,521 & 2,713 & 1,065 & 291 & 2,965 \\
\hline
\end{tabular}

Note: One-third or $29.6 \%$ of eligible households were not contacted or refused to participate in the survey. The main factor that affected the response rate was the timing - the data collection period overlapped with the July Naadam festival national holidays and summer vacation. At least three attempts were made to contact each household.

Source: IRIM. 2019. Support for Inclusive Education. Technical assistance consultant's report prepared for the Asian Development Bank. Manila.

25. The second stage of data collection was a follow-up survey of 562 households with a total of 657 children with disabilities between the ages of 2-17 (out of 1,337 children in total). Of the total households, $44 \%$ were located in Ulaanbaatar. ${ }^{19}$ The average number of family members is 4.5 and more than half of the households had 5-7 members. Households had an average of 2.4 children, and more than one-fifth of all households (21.5\%) are headed by women (the national average is $19.3 \%$ ). One in 10 household heads had no education (10.3\%), significantly higher than the national average of 3.6\%, while just over one-third had only junior secondary or lower (36.5\%), versus one-fourth nationally. The education level of mothers ranges from $11.5 \%$ uneducated to $30 \%$ with a bachelor's degree or higher (the share of mothers with a bachelor's degree or higher was more than 12 percentage points higher than the share of fathers). Among the school-aged children, enrollment was near-universal at $98 \%$. Most children (72\%) were living with both parents, while 19\% were living with only their mother.

26. The follow-up survey also collected a range of socioeconomic data and constructed a wealth index. The full survey results and details of the indicators comprising the wealth index ranking are available in the full IRIM survey report, ${ }^{20}$ but a few notable results are worth highlighting to present a broad picture of socioeconomic status. First, the vast majority of households (87\%) had an income lower than the national

18 NSO included children with anxiety difficulties only if depression and sadness occurred every day, but the IRIM survey team included children who answered either every day or every week (the other response options are once a month or once a year). The Washington Group recommends to evaluate children as at risk of having functional difficulties if they answer daily or weekly, depending on research objectives, context, and research methodologies. NSO also included only children who answered they were unable to perform a particular function, but IRIM also included children who answered that it was difficult to perform the function.

19 This is broadly representative of the distribution of the population: Ulaanbaatar's 1.5 million residents comprise approximately $46 \%$ of the country's total population of 3.24 million.

20 IRIM. 2019. Support for Inclusive Education. Technical assistance consultant's report prepared for the Asian Development Bank. Manila. 
average. ${ }^{21}$ Nearly one-third (31\%) of the households lived in a ger (against the national average of 37\%) and more than half of the households living in gers were in the Songino-Khairkhan district of Ulaanbaatar city. Of the households, 8 out of 10 lived in their own homes, while the rest rented. Nearly all households had access to electricity (only four did not, including two in Ulaanbaatar), 4 out of 10 households had an internet connection, and all households had at least one member with a cellphone. Nearly all households (96\%) owned a television. For transport, only 4 out of 10 households owned a car, while just under onequarter (24\%) owned a bicycle and $8 \%$ owned either a truck, jeep, or van. Just $4 \%$ owned a motorbike.

27. To assess the indicators of inclusion-inclusive culture, policies, practices, and physical environments (Chapter 4) -the study included extensive qualitative research through in-depth interviews and focus group discussions with 556 parents of older children (6-17), 101 parents of younger children (2-5), 76 teachers and school social workers, and 18 province and district-level education officials. In addition, the research team visited nine schools and kindergartens to complete observational checklists on physical accessibility.

28. Due to limited resources, this study focused on the perspectives of the key adults responsible for the education of children with disabilities. However, we would recommend that further research is carried out to also understand the perspectives of the children.

\section{TYPES OF DISABILITY, ACCESS TO EDUCATION, AND CAUSES OF DROPOUTS}

\subsection{Identifying Types of Disability}

29. Using the Washington Group/UNICEF child functioning module (section 1.3), the ADB screening survey identified 657 children with disabilities between the ages of 2-17 years, among whom only $19.6 \%$ were formally diagnosed with disabilities. In 2014, the Social Development Division of the governor's office in each aimag and district established branch commissions on health, education, and social welfare to coordinate and monitor services for children with disabilities aged 0-16. That same year, a central commission was established under the Ministry of Labor and Social Protection (MLSP). In theory, all the branch commissions in 21 aimags and nine districts have been operating since 2017, but the ADB survey found that the commission has approved only a small number of children's diagnoses. It appears that the commission's activities and services are still not reaching all soums and khoroos.

30. Eight out of 10 children with functional difficulties in the ADB survey have moderate or severe difficulties (Figure 4 ). A total of $22 \%$ of younger children aged $2-5$ and $16.7 \%$ of older children aged 6-17 have more than one disability. Multiple disabilities mean children face extra challenges in their social lives, learning environments, and with everyday routines. This requires special attention to their specific educational needs.

21 NSO. 2020. Household Socio-economic Survey 2018. Ulaanbaatar. The 2018 national average household monthly income was MNT1,181,067. 
Figure 4: Degree of Disability

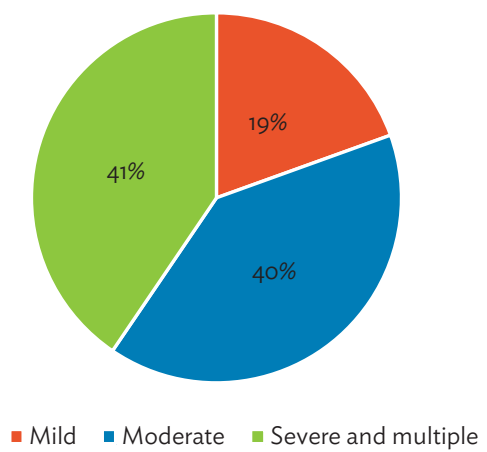

Source: IRIM. 2019. Support for Inclusive Education. Technical assistance consultant's report prepared for the Asian Development Bank. Manila.

\subsection{Access to Education}

31. SDG 4.1 aims to ensure that all girls and boys complete free, equitable, and quality primary and secondary education leading to relevant and effective learning outcomes. In Mongolia, children are enrolled in early childhood education (kindergarten) between the ages of $2-5$, in primary education from age 6 , in junior secondary education from age 12, and in high school from age 15. According to the 2018 MICS, school enrollment rates across Mongolia are $68 \%$ in early childhood education, $96 \%$ in primary education, and $93 \%$ in secondary education.

32. Most of the children aged 6-17 with functional difficulties (96.2\%) in the ADB survey attended school in 2018-2019 (Table 4). Of those attending school, 95.2\% went to regular schools, 1.7\% attended special schools, and $1.4 \%$ went to technical and vocational education and training (TVET) institutes. Among dropouts, 2.5\% were aged between 6-10 years, 3.5\% were between 11-14 years, and 6.7\% were between 15-17 years. Overall enrollment rates for children with functional difficulties are high and commensurate with national school enrollment rates according to the 2018 MICS. The percentage of children in specialized schools is much higher in Darkhan-Uul (3.7\%) and for older children (2.5\% of those $11-14$ years old). ${ }^{22}$ By the time children with functional difficulties are in high school (aged 15-17), only $88 \%$ are in mainstream schools, $2 \%$ are in specialized schools, and $7 \%$ in TVET.

33. Table 5 shows enrollment data for the children with disabilities aged 2-5: 63\% of preschool-age and $96 \%$ of school-aged children were enrolled in some kind of educational institution in school year 2018-2019, reflecting slightly lower rates than the national averages. Interviews revealed that the lower rate of school enrollment for preschool-aged children in Dornod and Ulaanbaatar was due to a lack of access to and overcrowding of kindergartens, as well as a lack of caretakers to take the children to and from school. Most of the children with functional difficulties are enrolled in regular (mainstream) kindergartens. Most of the children who do not attend kindergarten have no prior experience of receiving educational services, and most of them are boys.

34. According to Mongolia's 2018 MICS, dropout rates are $3.6 \%$ in primary school, $4.6 \%$ for junior secondary school, and $9.5 \%$ for high school. When the ADB survey team cross-referenced school dropout rates with the household wealth index it constructed, household wealth was found to have little effect on droupout rates at the primary level. However, starting from the junior secondary level, children

22 Darkhan is the only aimag that has a special school, the rest are in Ulaanbaatar. 


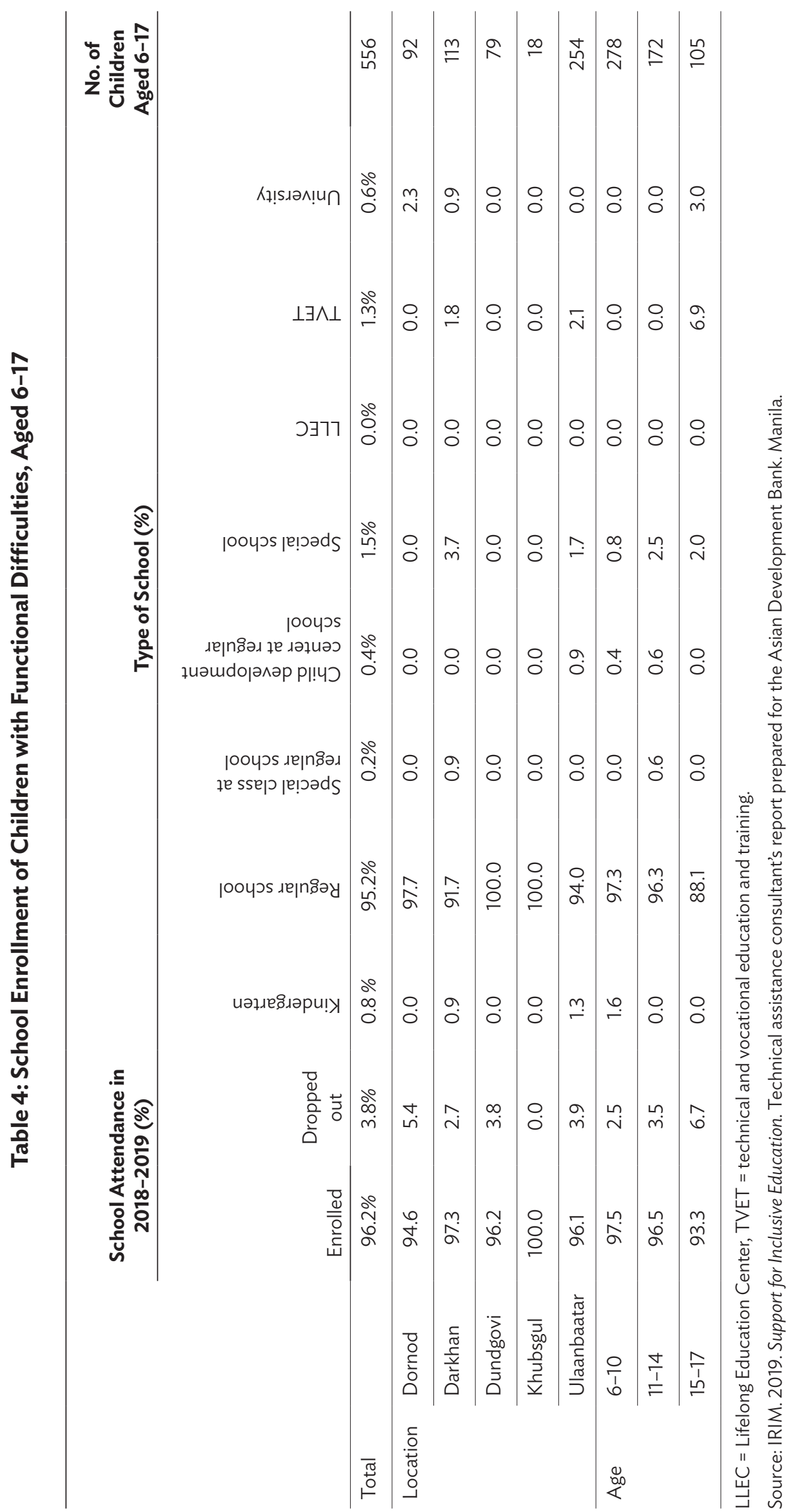


Table 5: Preschool Enrollment of Children with Functional Difficulties, Aged 2-5

\begin{tabular}{|c|c|c|c|c|c|c|c|}
\hline & & \multicolumn{2}{|c|}{ Preschool Enrollment (\%) } & \multicolumn{3}{|c|}{ Type of Kindergaten (\%) } & \multirow[t]{2}{*}{$\begin{array}{c}\text { Total } \\
\text { Children }\end{array}$} \\
\hline & & Enrolled & Not enrolled & 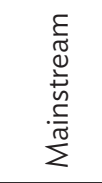 & $\begin{array}{l}\overline{\frac{\pi}{U}} \\
\bar{d} \\
\stackrel{0}{n}\end{array}$ & ৫ั & \\
\hline \multicolumn{2}{|l|}{ Total } & $63 \%$ & $37 \%$ & $94 \%$ & $5 \%$ & $2 \%$ & 101 \\
\hline \multirow[t]{5}{*}{ Location } & $\begin{array}{l}\text { Dornod } \\
\text { Province }\end{array}$ & 56 & 44 & 100 & 0 & 0 & 18 \\
\hline & $\begin{array}{l}\text { Darkhan } \\
\text { Province }\end{array}$ & 71 & 29 & 87 & 13 & 0 & 21 \\
\hline & $\begin{array}{l}\text { Dundgovi } \\
\text { Province }\end{array}$ & 75 & 25 & 100 & 0 & 0 & 8 \\
\hline & $\begin{array}{l}\text { Khuvsgul } \\
\text { Province }\end{array}$ & 67 & 33 & 100 & 0 & 0 & 3 \\
\hline & Ulaanbaatar & 61 & 39 & 94 & 3 & 3 & 51 \\
\hline \multirow[t]{5}{*}{ Age } & 2 & 30 & 70 & 100 & 0 & 0 & 23 \\
\hline & 3 & 52 & 48 & 92 & 0 & 8 & 25 \\
\hline & 4 & 82 & 18 & 100 & 0 & 0 & 17 \\
\hline & 5 & 68 & 32 & 85 & 15 & 0 & 19 \\
\hline & 6 & 100 & 0 & 94 & 6 & 0 & 17 \\
\hline
\end{tabular}

Source: IRIM. 2019. Support for Inclusive Education. Technical assistance consultant's report prepared for the Asian Development Bank. Manila.

from households in the lower quintiles drop out at a higher rate, and this increases sharply at the high school level. ${ }^{23}$ According to the ADB survey results, $3.8 \%$ of the children with functional difficulties have dropped out of school (6.7\% of children aged 15-17). This raises an issue for further research: since $87 \%$ of the households of children with functional difficulties in the ADB survey results are below the national average household income, we expected see an overall dropout rate for children aged 15-17 that is higher than the national average of $9.5 \%$, but instead, it is lower.

35. Among the out-of-school children, 81\% reported that they dropped out for personal reasons, $14.3 \%$ dropped out due to family-related reasons, and $2 \%$ dropped out because of a school-related reason. Caretakers and parents explained that personal reasons for dropping out included (in order of frequency) health conditions, lack of interest, and lack of or weak communication and interpersonal abilities. Familyrelated reasons for dropping out included inability to cover the cost of education, mobility and migration issues, lack of proper documentation, and lack of someone to take the child to and from school. Schoolrelated reasons were bullying by peers, and pressure from teachers and school staff.

36. Education department officials in Ulaanbaatar and the provinces-20 interviewed-described the following challenges in reaching out to and reenrolling students who dropped out (with the frequency of each response given in brackets):

23 UNICEF and NSO. 2018. Mongolia: Multiple Indicator Cluster Survey 2018. Ulaanbaatar. 
(i) parental lack of support and interest in educating their children (9);

(ii) lack of support mechanism for teachers who work with dropped-out students (7);

(iii) poor and impermanent registration and identification activities (6);

(vi) negative attitude of peers (6);

(v) children have no or little interest in attending school (6);

(vi) lack of legal-friendly regulations (5);

(vii) school administration's, teachers', and staff's reluctance to recruit the children (4); and

(viii) negative attitude of teachers and staff (1).

37. Box 1 illustrates the example of a girl who completed primary school, but dropped out of secondary school due to the lack of support from teachers and staff.

\section{Box 1: Insufficient Support at School}

[A student with a disability] was unable to study in secondary school among her peers. Her mother worked at her primary school, so was able to help [the student] with many things and supported her classes. As a result, [the student] was able to learn and graduate. When she enrolled in secondary school, there was no one to help or support her. Students and even teachers refused to support to her. Also, there were no ramps at the entrance of the school. For these reasons, she could not continue to attend school.

Source: Kazakh mother, Tsenkher soum, Bayan-Ulgii Province, 3 August 2019.

\section{THE LEGAL AND POLICY FRAMEWORK FOR INCLUSIVE EDUCATION IN MONGOLIA}

38. Mongolia's legal and regulatory framework for inclusive education for children with disabilities is comprehensive and wide-ranging, with several major pieces of legislation adopted in the past 5 years, and several MECSS policies and guidelines issued since 2018. However, with the rapid pace of development, there are gaps between the policy and the practice. This section presents major policies and a sample of parents' views, from the ADB survey, on their implementation.

\subsection{National Policies}

39. The $\mathbf{2 0 0 6}$ Education Law. According to Article 5.1.4, The citizens of Mongolia shall not be discriminated against on the basis of origin, language, race, age, gender, unique characteristics of development, health, social status, wealth, employment status, job position, religion and opinion. The equal opportunity and environment to learn in the mother tongue shall be ensured. Among survey respondents, $3 \%$ of parents with schoolchildren and $9 \%$ of parents of kindergarteners thought that the enabling environment was not welcoming to their children when they first entered the school or kindergarten, while $12.6 \%$ of parents thought that their children had difficulties adhering to school rules and procedures.

40. The State Policy on Education, 2014-2025 says that all formal and nonformal educational institutions must be able to provide accessible services for the educational needs of all age groups. The ADB survey asked parents whether adjustments to the curriculum are possible based on their children's special needs. About one-third of the parents of both kindergarten and school children responded that they do not think curriculum adjustments are possible. More than half of parents (56\%) thought it was not possible to access private tutoring for their children to catch up based on their needs. 
41. Sustainable Development Goal 4: Inclusive and equitable education. SDG target 4.a aims at eliminating gender disparities in education and ensuring equal access to all levels of education and vocational training for the vulnerable, including persons with disabilities, indigenous peoples, and children in vulnerable situations. The perception of children without disabilities and their parents toward children with disabilities is also important. In the ADB survey, $13 \%$ of teachers said they received complaints from parents of children without disabilities who are attending school with children with disabilities.

42. The 2016 Preschool Education Law. Amendments to the law in 2016 highlighted shared learning environments for children with a moderate level of disability and provided for regular classes and additional salary for kindergarten teachers who work with children with disabilities. Just over $28 \%$ of parents with kindergarten children said they receive information such as the kindergarten policy from staff, while $15 \%$ of parents answered that the kindergarten policies and values are displayed in the entrance areas. Nearly one-third of parents (30\%) noted that their children are not enrolled in a kindergarten within the designated distance.

43. The $\mathbf{2 0 1 6}$ Law of Mongolia on the Rights of Persons with Disabilities. This law states that persons with disabilities shall have equal access to education and vocational education, and all the educational institutes shall ensure persons with disabilities-friendly learning environments. The ADB survey found that some aimags provide good services, such as special classes and clubs, next to their local regular schools, with funding from own resources. Article 16.2 specifies that teachers and social workers of all educational institutions of higher education shall acquire teaching methods and techniques that meet the specific needs of students with disabilities. However, survey results show considerable gaps in teachers' and social workers' awareness of disability. Some aimags have a dedicated officer in charge of children with disabilities, while others do not (instead, the officer in charge of primary education has these added responsibilities). The most common difficulties reported by teachers include low incentives for working with children with disabilities, lack of human resources specializing in inclusive education, and lack of evidence-based training programs and methodologies.

44. The Joint Ministerial Order on Comprehensive Support to Children with Disabilities (November 2018) was jointly issued by the MLSP, MECSS, and the Ministry of Health to clarify the role and functions of the national and branch commissions for health, education, and social welfare as the lead institutions in charge of enrolling children with disabilities in comprehensive health, education, and social assistance services. Section 3.6 on supporting inclusion in education services outlines creating inclusive learning environments, applying principles of universal design, establishing enrollment support councils to define and meet the needs of children with disabilities, and creating individual development plans.

45. The National Program on the Rights, Participation, and Development of Persons with Disabilities, 2018-2022. Objective 2 highlights that all levels of education shall be accessible to disabled citizens. Objective 3 indicates that a situation analysis on children with disabilities will be conducted at the national level. Objective 4 describes disability-friendly social welfare services and that the commission on health, education, and social welfare should define children with disabilities. However, as of 2019, the commission had not released any data or reports.

\subsection{Selected Ministry of Education, Culture, Science and Sports Regulations and Policies}

46. Individual development plans (2018). MECSS Decree No. 155 of February 2018 issued a template for individual development plans (IDPs). Designed for use in school and at home, IDPs design a training plan, incorporate teacher and specialist expertise, and create a support mechanism for children based on their actual development stage. The IDP should address and support a child's unique development characteristics and needs. IDPs were introduced in the 2018-2019 school year, and are now developed for every child with disabilities in school. However, some teachers lack the knowledge, 
capacity, and experience to develop appropriate IDPs. The ADB survey asked parents of children with disabilities in regular schools whether their child has an IDP based on their special needs and attributes. More than half (56\%) of parents answered no. Teachers were asked whether it is possible to make a change in the curriculum based on students' special needs and attributes: $21 \%$ of teachers said no, while $5 \%$ did not know. About one-third (30\%) of teachers said they always consider disability and special needs of the children when organizing group projects, while half (49\%) said mostly, $9 \%$ mostly do not consider them, and 12\% never consider them. This shows the substantial gap between teacher practices and parents' expectations. Only $40 \%$ of teachers said that students are always able to get homework support from the teacher, while $42 \%$ said they are mostly able to. Only $9 \%$ of of teachers answered mostly no, and $3 \%$ said never.

47. Assessment of Primary and Secondary Students and Teaching Quality (2018). MECSS decree No. A/425 of June 2018 has been implemented since the start of the 2018-2019 school year. This procedure states that the developmental progress and changes of students who are studying based on an IDP formulated around their unique disability and learning abilities should be assessed by process evaluation. Furthermore, enrollment in the next grade and graduation should be decided based on an evaluation process by the examination commission. This procedure represents a step forward as it incorporates flexible regulations that allow assessment of students based on their own progress, thus enabling inclusive education. The ADB survey found that $63 \%$ of teachers feel they lack systematic provisions to assess the learning achievements of children with disabilities. Teachers' knowledge, skills, and experience with flexible assessment should be improved. Parents' participation plays an important role. The results show that $15 \%$ of teachers said they always ask for parents' suggestions when evaluating the student's homework, $45 \%$ of teachers mostly ask for parents' suggestions, while $27 \%$ mostly do not ask, and $13 \%$ never do. Participation of children with disabilities themselves is equally important: $24 \%$ of teachers reported that they always provide opportunities for students to choose homework to develop their interests and knowledge, while $59 \%$ mostly do, and $17 \%$ of teachers mostly do not.

48. Cost calculation of special training institutions and provision of additional funding. Regulation A/185 Article 3.2 provides that the normative cost for each learner at educational institutions for children with disabilities can be increased three times. Article 3.3 says that the same arrangement will be put in place for regular schools and kindergartens. In other words, regular schools and kindergarten may receive three times more funding for children with disabilities. However, this provision only came into force in the spring of 2019.

49. Guidance on Inclusive Education of Children with Disabilities in Mainstream Schools (2019). MECSS adopted Regulation A/292 in May 2019 to establish school support teams aimed at promoting inclusive learning opportunities and an inclusive environment, based on children's needs and unique identity, by cooperating with special schools and parents and establishing "child development support classrooms" or resource centers. The funding of the new activities should come from schools' annual budget. According to the ADB survey, $34 \%$ of parents of children with disabilities said their children have the opportunity to participate in extracurricular clubs or activities based on their preferences, but $27 \%$ said they do not. When asked whether their child seeks assistance from schoolteachers and staff when they need help, $27 \%$ said no, while $12 \%$ did not know.

50. Many of the findings in this section confirm that Mongolia's new system to support inclusive education is still nascent. These findings are not necessarily conclusive about the quality of education or inclusion itself. They simply confirm that measures are not yet fully effective or fully implemented. 


\section{CONSTRUCTING MONGOLIAN INDICATORS OF INCLUSIVE EDUCATION}

51. To define the common challenges and gaps in educational environments for Mongolian children with disabilities, the ADB study collected quantitative and qualitative data from parents, teachers, and social workers and through observation, based on a framework of inclusive education indicators developed by Tony Booth and Mel Ainscow's Index of Inclusion. ${ }^{24}$ The framework explores inclusion and exclusion along three interconnected indicators of school improvement: creating inclusive cultures, producing inclusive policies, and evolving inclusive practices. For the Mongolian context, the research team added a fourth indicator: building inclusive physical environments.

52. For this study, the inclusive education indicators are as follows:

(i) Inclusive cultures. Whether the school has developed safe, acceptable, and friendly environments, cultures, and values for all children. An inclusive culture is crucial to creating environments that create high-quality learning opportunities and allow every child to feel accepted, welcomed, and valued. This indicator is based on responses to nine questions for parents of schoolchildren and eight questions for parents of kindergarten children.

(ii) Inclusive policies. Whether the school's internal policies, procedures, and plans aim to promote learners' participation, reach out to each and every child, and minimize discrimination. This indicator is based on six questions for parents of school children, four questions for parents of kindergarten children, and questions for teachers on policy.

(iii) Inclusive practices. How the school ensures implementation of policy that incorporates inclusive principles and considers cultural factors. This indicator is based on six questions for parents of schoolchildren and five questions for parents of kindergarten children.

(vi) Inclusive physical environments. Whether the school has accessible internal and external environments that include additional equipment and materials when needed. This indicator is based on direct observations by the study team.

53. For three of the indicators-inclusive cultures, policies, and practices-the score is the share of parents who believe their child's school or kindergarten is performing well on that indicator and gave positive responses. The score for inclusive physical environments is based on independent assessment of the outdoor environment, the indoor environment, and the classroom environment. ${ }^{25}$

\subsection{Inclusive Cultures}

54. This indicator gauges the level of child-friendly culture and values of mutual respect and assesses whether selected schools and kindergartens successfully curb discrimination against children with disabilities. The inclusive culture indicator has two subcomponents:

24 Booth, T. and M. Ainscow. 2002. Index for Inclusion: Developing Learning and Participation in Schools. United Kingdom: Center for Studies on Inclusive Education.

25 How to interpret the scores in the following sections: for the inclusive community and inclusive values sub-indicators, the score is the average percentage of respondents who gave positive responses to the questions while the inclusive cultures score is the average of the scores for these two sub-indicators. The inclusive policy and inclusive practice scores are the average percentage of respondents who gave positive responses to the questions. The inclusive physical environments indicator was scored by school rather than province; the score for each of the three dimensions (outdoor environment, indoor environment, classrooms) is the percentage of items on the checklist that are in place (the higher, the better); and the overall score is the average of the three scores. 


\section{(i) Inclusive communities}

(a) whether people communicate with each other politely and respectfully

(b) whether teachers communicate politely with children, considering every child's unique identity and special needs

(c) whether the school provides a safe learning environment

(d) whether the school provides a discrimination-free environment

(e) whether teachers and staff promote cooperation and teamwork among children

(ii) Inclusive values

(a) whether teachers treat children equally and impartially

(b) whether the school has a high standard of ethics with exemplary teachers

(c) whether the school encourages children to resolve disputes and conflicts in nonviolent ways

(d) whether teachers accept the unique identity of every child and consider such identities during activities

55. The inclusive culture scores for the selected schools and kindergartens are shown in Table 6. Schools had an average score of 62 while kindergartens averaged an inclusive culture score of 52 . These results underscore that an inclusive learning culture is not yet present for every child in Mongolia. Scores from Dundgovi were slightly higher than those in other areas.

Table 6: Inclusive Culture Scores

\begin{tabular}{|c|c|c|c|c|c|c|}
\hline & Dornod & Darkhan & Dundgovi & Khuvsgul & UB & Average \\
\hline Inclusive school communities & 59 & 59 & 75 & 60 & 63 & 63 \\
\hline Inclusive school values & 59 & 66 & 66 & 54 & 62 & 62 \\
\hline $\begin{array}{l}\text { Overall inclusive school } \\
\text { cultures }\end{array}$ & 59 & 63 & 71 & 57 & 63 & 62 \\
\hline $\begin{array}{l}\text { Inclusive kindergarten } \\
\text { communities }\end{array}$ & 43 & 58 & 69 & 67 & 46 & 56 \\
\hline Inclusive kindergarten values & 37 & 46 & 56 & 50 & 44 & 47 \\
\hline $\begin{array}{l}\text { Overall inclusive kindergarten } \\
\text { cultures }\end{array}$ & 40 & 52 & 63 & 58 & 45 & 52 \\
\hline
\end{tabular}

$\mathrm{UB}=$ Ulaanbaatar.

Source: IRIM. 2019. Support for Inclusive Education. Technical assistance consultant's report prepared for the Asian Development Bank. Manila.

56. The data for questions on inclusive community and inclusive values for parents of school-aged children with disabilities are shown in Figure 5. In terms of location, selected schools from Dundgovi Province ranked the highest in terms of inclusive culture, while selected schools from Ulaanbaatar city and Darkhan-Uul Province ranked lowest. The lowest-rated question asked whether children are free from all types of discrimination in the school environment.

57. It is important to highlight that parents commonly answered "I don't know" to many of the questions. This suggests that parents lack knowledge about the school and teachers' everyday actions, including those involving student conflict management. 
58. Inclusive culture in kindergarten used the same method for measuring the school environment (Figure 6). The survey collected data from 110 caretakers of children with functional difficulties aged 2-5 from selected provinces and districts. In terms of location, selected kindergartens from Khuvsgul and Dundgovi ranked highest, while selected kindergartens from Ulaanbaatar City and Dornod provinces ranked relatively lower. The lowest ranking indicator was whether children are free from all types of discrimination in the kindergarten environment. It is interesting to note that schools scored much lower than kindergartens on this indicator, but much higher across the other indicators. Most of the indicators for inclusive values were also low. The lowest ranking indicator was whether teachers accept the unique identity of each child and incorporate it into their training.

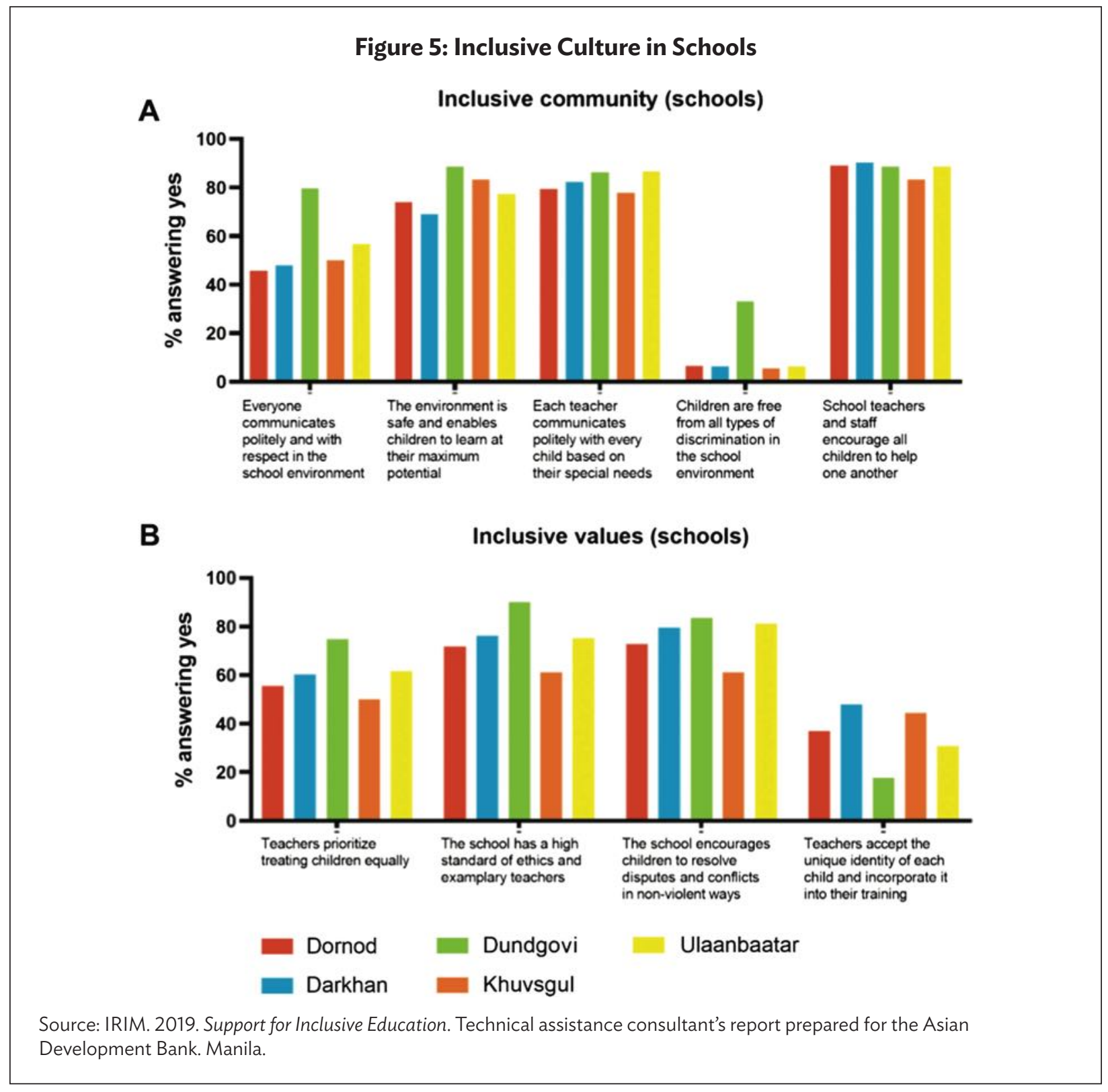


Figure 6: Inclusive Culture in Kindergartens

A Inclusive community (kindergartens)

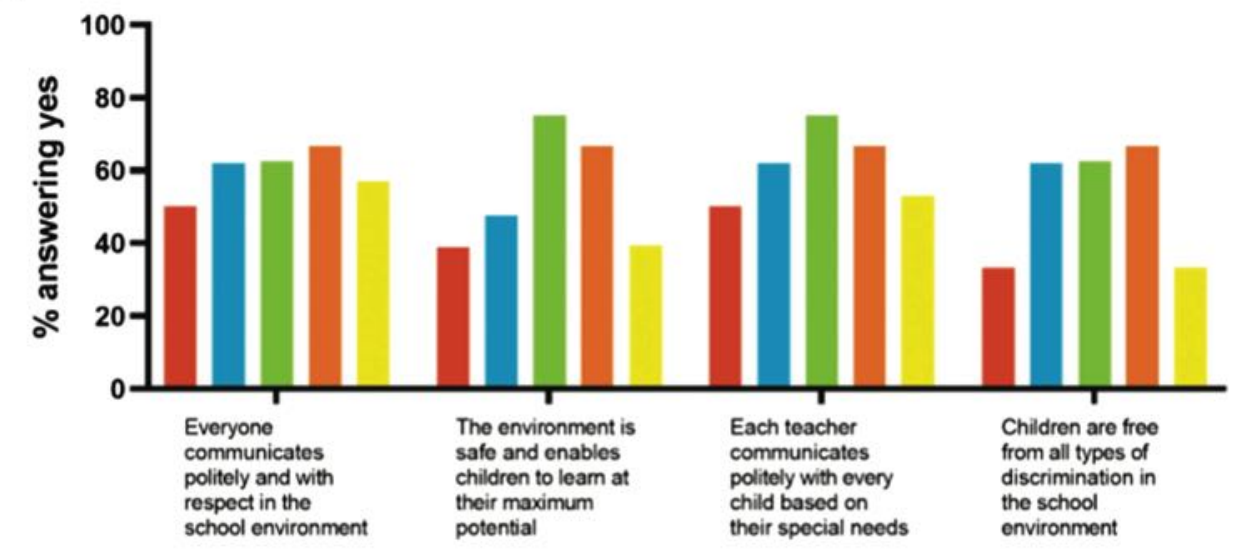

B Inclusive values (kindergartens)

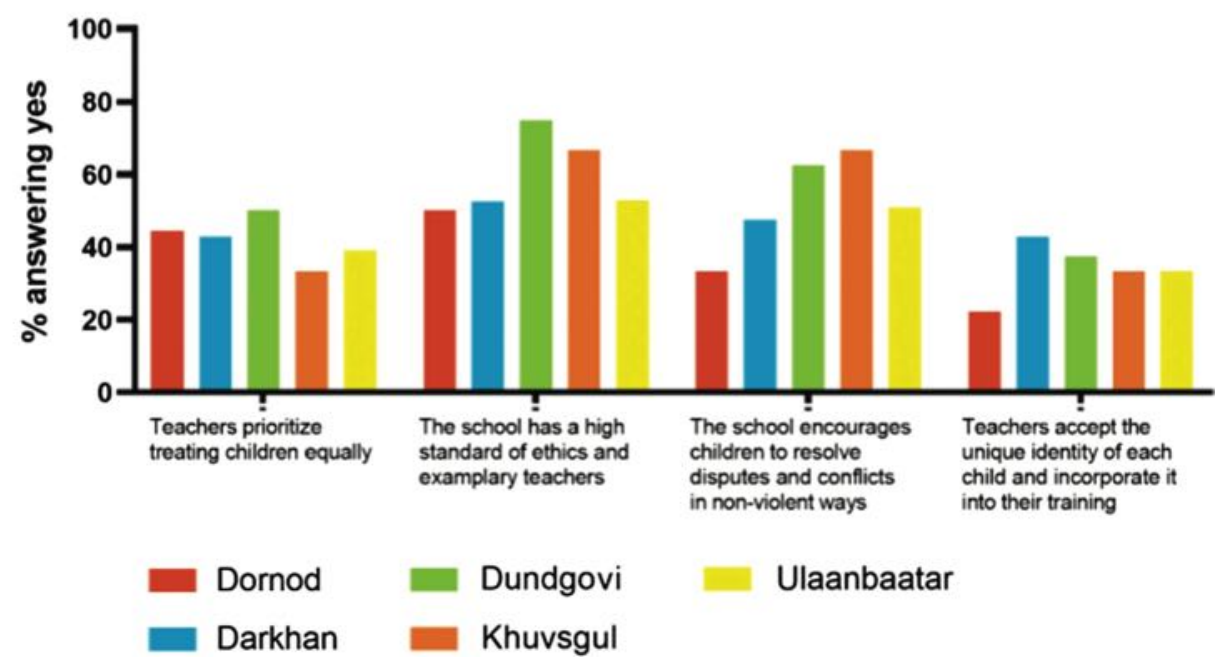

Source: IRIM. 2019. Support for Inclusive Education. Technical assistance consultant's report prepared for the Asian Development Bank. Manila.

59. The survey posed a range of additional questions to parents. ${ }^{26}$ Responses indicate that discrimination in the school environment is common, and teachers do not consider the special needs of the children in their teaching, particularly for children who have speaking difficulties, are not confident, are slow to adapt to changes, and/or have problems memorizing. There are many children with functional difficulties who are successfully studying with their peers in regular schools. However, the interviews revealed that teachers sometimes neglect, discriminate, or are annoyed by children with functional difficulties. Between $5 \%$ and $7 \%$ of surveyed parents of children with functional difficulties report their child has no friends at school and are not eager to attend school. One striking finding related to parents' perception of safety (Figure 7): more than one-third (34\%) of parents of school-aged children did not feel sure that their child was completely safe at school. The proportion for parents of kindergarten children was $21 \%$.

26 Full findings are available in IRIM. 2019. Support for Inclusive Education. Technical assistance consultant's report prepared for the Asian Development Bank. Manila. 


\section{Figure 7: Parents' Perceptions of Safety (\%)}

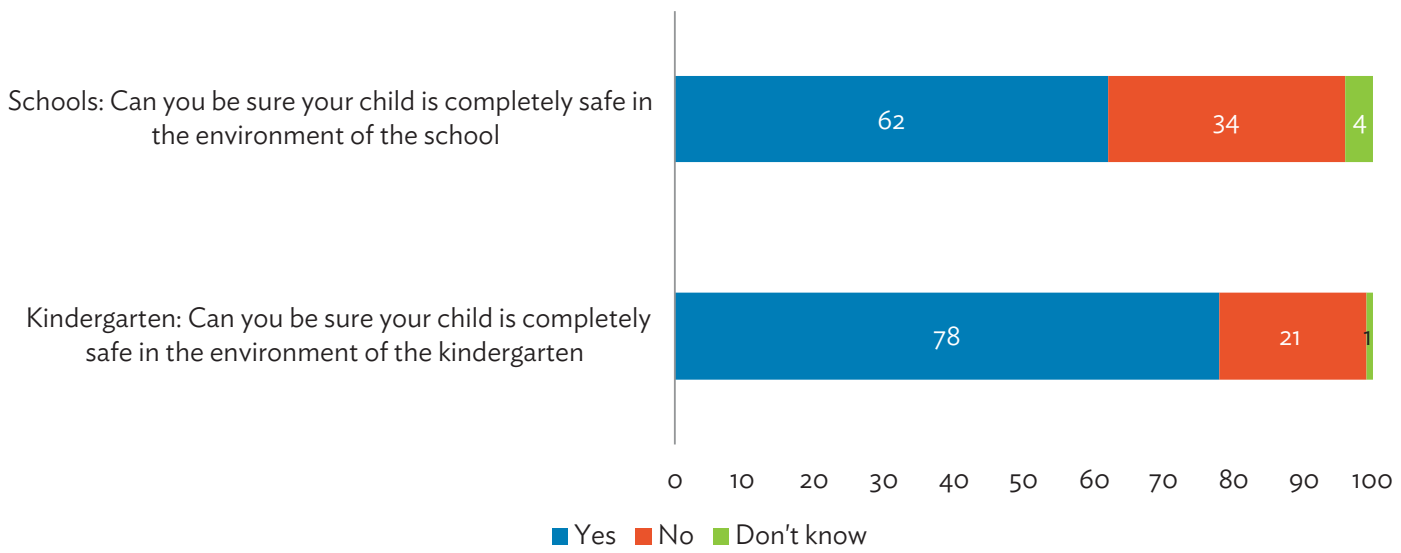

Source: IRIM. 2019. Support for Inclusive Education. Technical assistance consultant's report prepared for the Asian Development Bank. Manila.

60. The ADB survey results underscore that creating inclusive cultures in Mongolian schools still has a long way to go, but it appears to be beginning to develop in kindergartens. According to some parents, kindergartens and schools in Dundgovi had more inclusive cultures than other provinces. With regard to functional difficulties, children with physical challenges including those related to sight, hearing, mobility, and speaking, as well as children with unique cultural needs, face many challenges in kindergarten environments. Meanwhile, some parents report that school children face comparatively more cognitive and communication skill challenges including making friends, starting a conversation, learning, and memorizing. In both schools and kindergartens, there were frequent reports of discriminatory attitudes toward a child's physical appearance, disability, and unique identity. The surveyed parents highlighted that children's special needs are not fully considered in teaching and learning (Box 2).

\section{Box 2: How Do Teachers Work with Your Child?}

My child's teachers teach the whole class, it is rare that a teacher specifically works with any one child. The physical education teacher knows my child's condition and treats her differently. The math teacher said: "how could your child learn anything, you should teach her yourself, or send her to a special school." I've spoken with the teachers and never get a positive response. They say it is difficult to teach or test my child. I asked the math teacher: if my child can't solve all of the math problems, can't you give marks on the tasks she is able to do? The teacher said no, because it was the final exam for the school year, and my child had to learn.

Source: Interview with a mother of a child with cerebral palsy, Orkhon Province, 3 August 2019.

\subsection{Inclusive Policies}

61. The inclusive policies indicator for both schools and kindergartens is shown in Table 7.

Table 7: Inclusive Policy Scores

\begin{tabular}{lcccccc}
\hline & Dornod & Darkhan & Dundgovi & Khuvsgul & Ulaanbaatar & Average \\
\hline Inclusive school policies & 59 & 58 & 65 & 63 & 65 & 62 \\
\hline Inclusive kindergarten policies & 38 & 44 & 59 & 42 & 42 & 45 \\
\hline
\end{tabular}

Source: IRIM. 2019. Support for Inclusive Education. Technical assistance consultant's report prepared for the Asian Development Bank. Manila. 
62. Figure 8 presents the detailed data underlying calculation of the inclusive policy scores. This includes parents' views on inclusive policy in schools and kindergartens. Parents with children of kindergarten age assessed the policy environment along four indicators, while parents of school-aged children assessed six indicators. Teachers were also asked about inclusive policy and their answers were significantly more positive than parents. This suggests a mismatch between the perceptions of parents and teachers. Unless this is resolved, it is unlikely that teachers will be focusing on improving the aspects of inclusive policy that most concern parents.

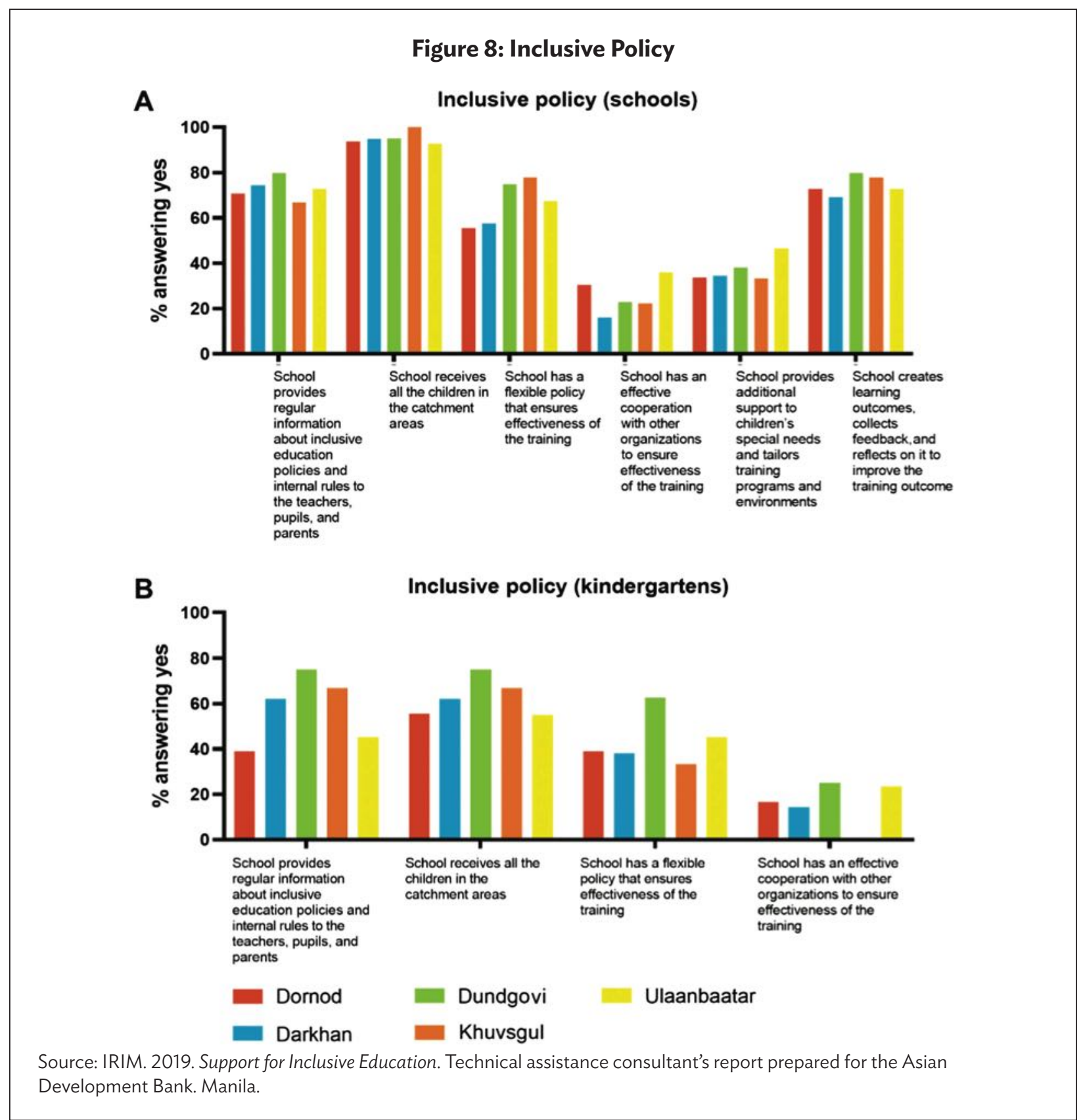

63. Schools' cooperation with other professional organizations to improve educational outcome was particularly weak, as was adaptability and responsiveness of the training programs to the needs of children with disabilities. This is especially true for children with speech difficulties and memory problems (IRIM 2019). 
64. In conclusion, despite the favorable legal and policy environment (discussed in Chapter 3), the inclusive policies scores suggests implementation is not adequate and further improvements are needed. To provide effective education to children with disabilities, schools should strengthen coordination with professional organizations, disabled people's organizations, and other inclusive education stakeholders and ensure their engagement in planning and decision making.

\subsection{Inclusive Practices}

65. By measuring inclusive practices, the ADB survey aimed to determine whether schools and kindergartens ensure equal participation of children with disabilities. The overall inclusive practices score for schools and kindergartens is presented in Table 8, based on data from parents on six school indicators and five kindergarten indicators.

\section{Table 8: Inclusive Practice Scores}

\begin{tabular}{lcccccc}
\hline & Dornod & Darkhan & Dundgovi & Khuvsgul & Ulaanbaatar & Average \\
\hline Inclusive practices in schools & 56 & 49 & 67 & 39 & 54 & $\mathbf{5 3}$ \\
\hline $\begin{array}{l}\text { Inclusive practices in } \\
\text { kindergartens }\end{array}$ & 22 & 39 & 50 & 27 & 31 & $\mathbf{3 4}$ \\
\hline
\end{tabular}

Source: IRIM. 2019. Support for Inclusive Education. Technical assistance consultant's report prepared for the Asian Development Bank. Manila.

66. Results indicate that kindergartens score relatively low on inclusive practice with an overall score of 34. They were insufficient both in promoting an acceptance of diversity and in teaching children how to respect others' differences. They also performed poorly in terms of providing additional activities to meet the different needs of children with disabilities. These issues were especially true for children with visual and hearing impairment, and mobility and motor difficulties. Schools fared slightly better with a score of 53. The schools performed similarly in educating children to recognize and respect diversity at school. They were also weak in cooperating with inclusive education stakeholders to improve learning outcomes (see Figure 9 for details). Dundgovi aimag saw the best performance.

67. In the school environment, parents of children with speech difficulties, children with hearing impairment, children with learning and remembering difficulties, and children with concentration problems often faced problems in inclusive education. Schools need to address these issues to create inclusive environments at school. Overall, the results show that the inclusiveness of educational institutions' environments is not sufficient. Despite increasing enrollment of children with functional difficulties in regular kindergartens and schools, the educational institutions' environments still cannot ensure inclusiveness standards. Besides this, there is an urgent need to adapt and revise school curricula, teaching, and teacher training methodologies to meet the needs of children with disabilities.

68. The survey results show that kindergartens inadequately addressed special needs of children with visual, hearing, and/or mobility impairment, while schools were most likely to be insufficient in meeting the needs of children with learning and concentration difficulties, and children with information retrieval (memory) difficulties and communication problems.

69. Overall, the results suggest that schools and kindergartens are doing better on policy and culture as far as parents are concerned, but parents are not yet feeling the effects in terms of practice. This is in keeping with the introduction of new national policies and legislation that has yet to be fully and effectively implemented. Training of teachers and ensuring additional resources are provided in the classroom seem to be needed to really shift from policies and ideas to implementation in practice. These and other recommendations are summarized in Chapter 5. 
Figure 9: Inclusive Practice
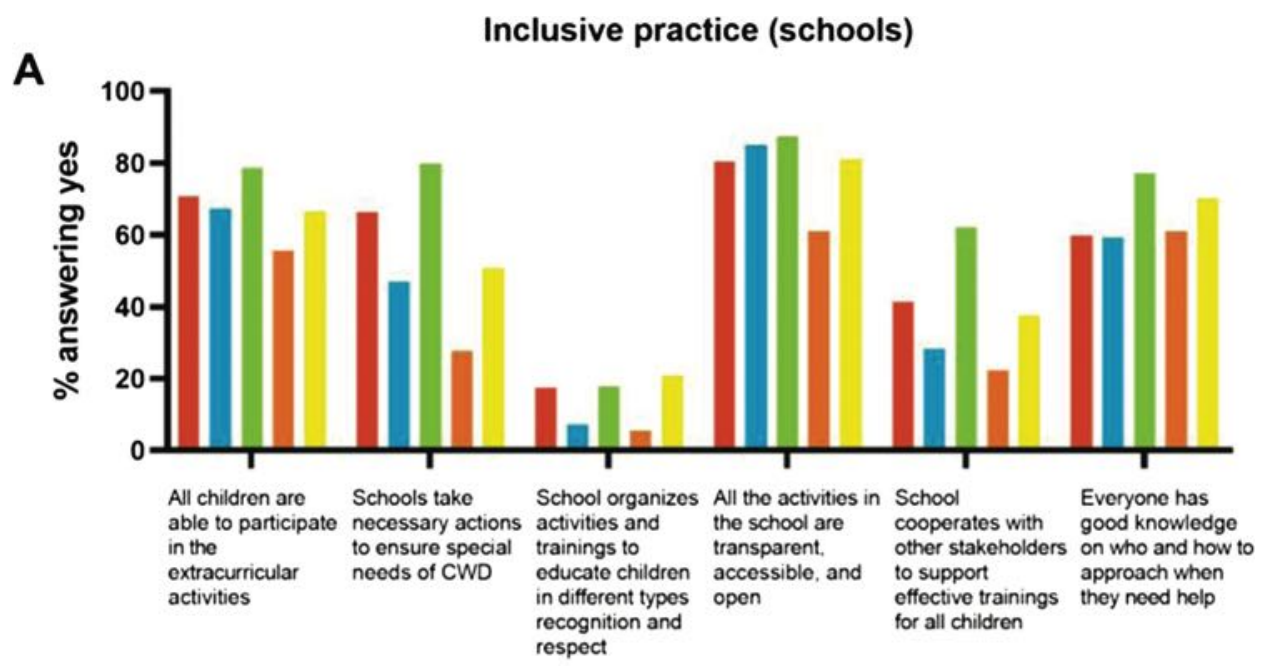

B

Inclusive practice (kindergartens)

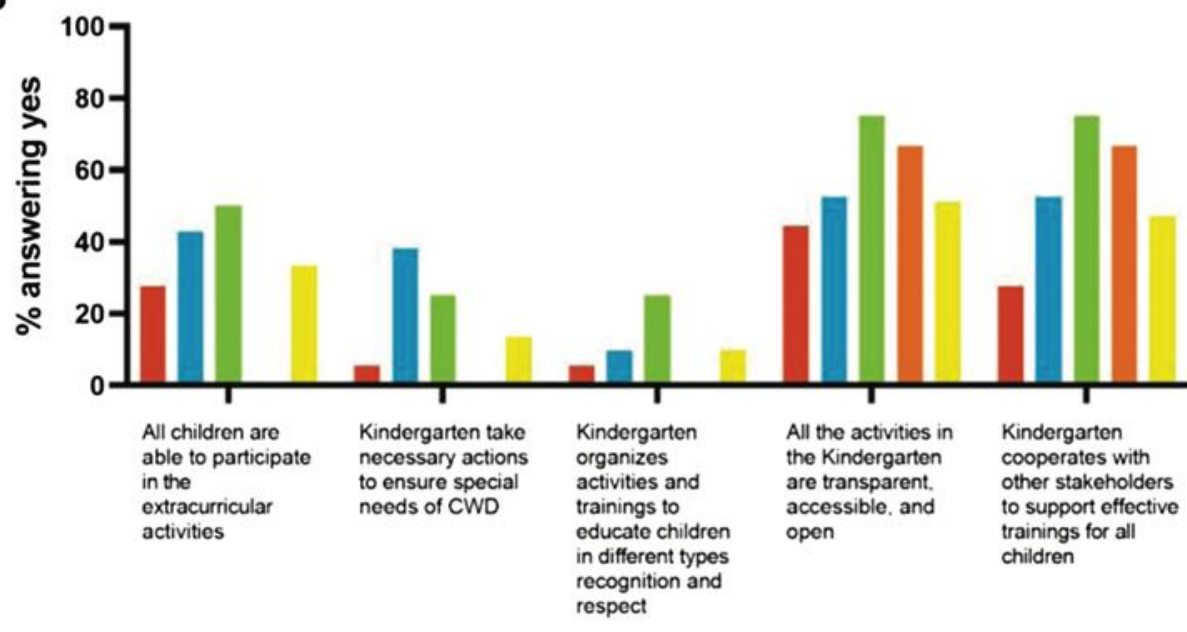

$\begin{array}{ll}\text { Dornod } & \text { Dundgovi Ulaanbaatar } \\ \text { Darkhan } & \text { Khuvsgul }\end{array}$

CWD = children with disabilities.

Source: IRIM. 2019. Support for Inclusive Education. Technical assistance consultant's report prepared for the Asian Development Bank. Manila.

\subsection{Inclusive Physical Environments}

70. The ADB survey aimed to assess the inclusive physical environment of selected aimag and district schools and kindergartens in terms of the child-friendly, needs-based, and supportive educational facilities essential for children with disabilities. The analysis draws on data from 76 school administrators, educators, and staff; interviews with more than 650 caregivers (mothers or guardians); and observations of the school environment using a checklist of features that should be present.

71. In assessing issues and challenges, $91 \%$ of teachers expressed that they had insufficient teaching and learning materials and facilities, while $43 \%$ reported that a lack of accessible infrastructure and the 
overall unpreparedness of schools were the main challenges. These results demonstrate that teachers and educators believe that learning environments should be improved, with a specific focus on increasing the supply of accessible learning facilities and teaching and learning materials. Table 9 summarizes the survey of facilities using an observational checklist. Both outdoor and indoor environment facilities and the overall physical environment of selected schools and kindergartens demonstrate significant gaps.

Table 9: Results of Observational Checklist Survey

(\% of items on the checklist that are present)

\begin{tabular}{|c|c|c|c|c|c|}
\hline & & $\begin{array}{c}\text { Outdoor } \\
\text { Environment }\end{array}$ & $\begin{array}{c}\text { Indoor } \\
\text { Environment }\end{array}$ & Classrooms & $\begin{array}{c}\text { Physical } \\
\text { Environment }\end{array}$ \\
\hline \multicolumn{6}{|l|}{ Schools } \\
\hline Dundgovi & School no. 3 & 50 & 40 & 71 & 54 \\
\hline Dornod & School no. 1 & 40 & 76 & 43 & 53 \\
\hline UB, SK & School no. 42 & 80 & 68 & 0 & 49 \\
\hline Khuvsgul & Tsagaannuur School & 20 & 32 & 29 & 27 \\
\hline Darkhan & School no. 12 & 10 & 32 & 71 & 38 \\
\hline \multicolumn{6}{|c|}{ Kindergartens } \\
\hline Dornod & Kindergarten no. 8 & 50 & 56 & 57 & 54 \\
\hline Darkhan & Kindergarten no. 7 & 10 & 60 & 100 & 57 \\
\hline Dundgovi & Kindergarten no. 3 & 60 & 40 & 71 & 57 \\
\hline UB, SK & Kindergarten no. 253 & 30 & 76 & 0 & 35 \\
\hline
\end{tabular}

SK = Songino-Khairkhan, UB = Ulaanbaatar.

Source: IRIM. 2019. Support for Inclusive Education. Technical assistance consultant's report prepared for the Asian Development Bank. Manila.

72. The study also collected information from 18 aimag and district education officers about active education support programs, interventions, or organizations working to improve learning environments for children with disabilities at the selected schools and kindergartens during the 2018-2019 academic year. This information is presented in Table 10. In the previous academic year, education officers from rural areas collaborated with aimag and district governors' offices on projects to supply teaching materials and to refurbish infrastructure and learning environments. They also collaborated with international organizations and nongovernment organizations to provide teaching materials and textbooks, and to improve the school environment.

73. Children with disabilities face several difficulties when it comes to physical environments. The survey assessed school settings in three main categories: (i) indoor and outdoor environments, (ii) accessibility of the physical environment, and (iii) projects to improve the physical environment.

74. Indoor and outdoor environments. In the survey of 556 mothers or guardians with older children (6-17 years old), 35\% reported that their children faced difficulties with the outdoor school environment (Figure 10). Specifically, $26 \%$ reported difficulties associated with commuting between home and school, $12 \%$ noted problems utilizing physical education facilities, $10 \%$ were related to entering the grounds, and $6 \%$ were about entering the building main entrance. One-fourth of the 101 mothers or guardians with younger children (2-5 years old) reported that their children have difficulties with the outdoor environment. Breaking this down by type of issue, $20 \%$ said problems were related to using 
public transport to and from kindergarten, $9 \%$ said they were related to using the playground, while $9 \%$ noted they were associated with entering the kindergarten fence or main entrance.

\section{Table 10: Stakeholder Collaboration for Inclusive Education}

(No. of activities)

\begin{tabular}{|c|c|c|c|c|}
\hline Type of Activity & $\begin{array}{l}\text { Collaboration } \\
\text { with the } \\
\text { Governor's } \\
\text { Office }\end{array}$ & $\begin{array}{c}\text { Collaboration } \\
\text { with } \\
\text { International } \\
\text { Organizations or } \\
\text { NGOs }\end{array}$ & $\begin{array}{l}\text { Collaboration } \\
\text { with } \\
\text { Kindergarten or } \\
\text { Khoroo }\end{array}$ & $\begin{array}{c}\text { Collaboration } \\
\text { with School or } \\
\text { LLEC }\end{array}$ \\
\hline \multicolumn{5}{|l|}{ No. of Activities } \\
\hline Training for parents & 4 & 4 & 1 & 6 \\
\hline Training for teachers & 3 & 6 & 1 & 4 \\
\hline $\begin{array}{l}\text { Accessible infrastructure and } \\
\text { refurbishment for people with disabilities }\end{array}$ & 6 & 6 & 2 & 5 \\
\hline $\begin{array}{l}\text { Supply with teaching aid, and technical } \\
\text { facilities for children with disabilities }\end{array}$ & 4 & 8 & 1 & 0 \\
\hline Public education campaigns & 3 & 8 & 0 & 5 \\
\hline Experience exchange programs & 1 & 3 & 2 & 4 \\
\hline Projects to improve school infrastructure & 4 & 4 & 1 & 1 \\
\hline $\begin{array}{l}\text { Projects to supply with teaching } \\
\text { materials and books }\end{array}$ & 3 & 5 & 0 & 1 \\
\hline None & 0 & 0 & 0 & 0 \\
\hline Total no. of activities & 28 & 44 & 8 & 26 \\
\hline
\end{tabular}

LLEC = Lifelong Education Center, NGO = nongovernment organization.

Source: IRIM. 2019. Support for Inclusive Education. Technical assistance consultant's report prepared for the Asian Development Bank. Manila.

\section{Figure 10: Problems with Outdoor Environments at Schools and Kindergartens}

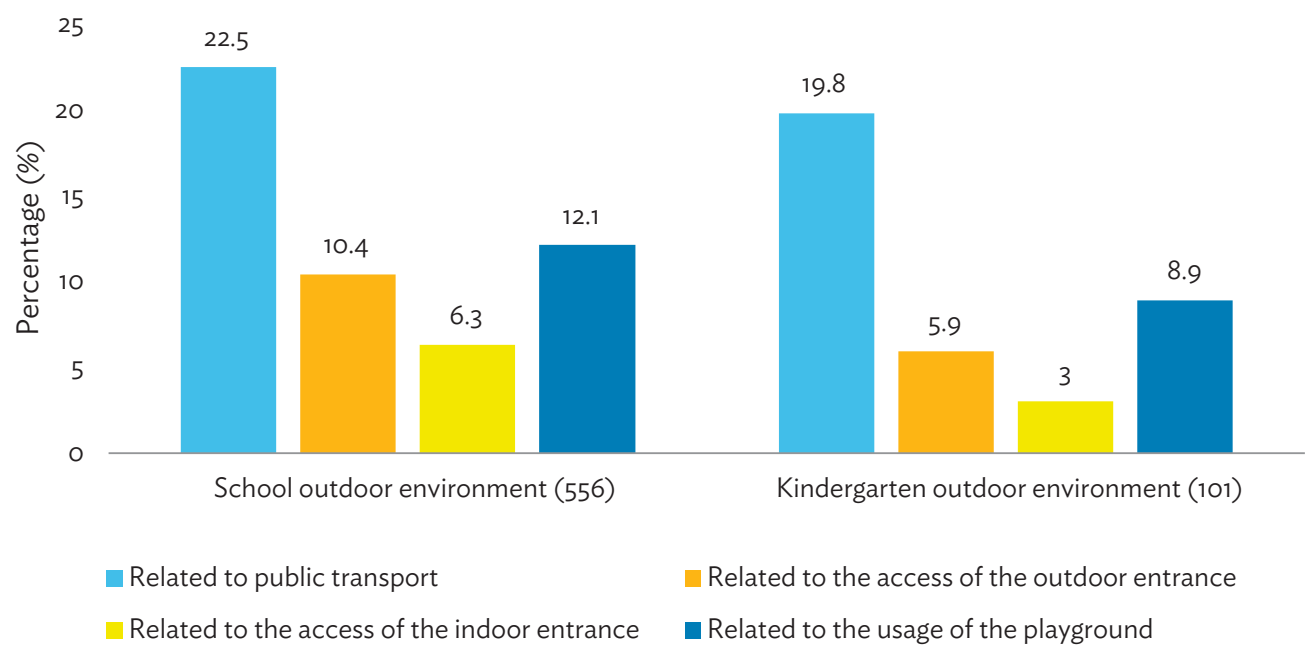

Source: IRIM. 2019. Support for Inclusive Education. Technical assistance consultant's report prepared for the Asian Development Bank. Manila. 
75. Based on the observation of kindergarten and school outdoor environments, children with disabilities were unable to access the environment independently without the help of support equipment. Safety measurements were insufficient and need improvement. The photos below show two examples where children with wheelchairs are not able to get from the bus stop to the kindergarten facility. In the first photo, the building is located far from the bus stop and the road is not paved. The second shows a damaged paved road. All photos in this section were taken in July 2019.

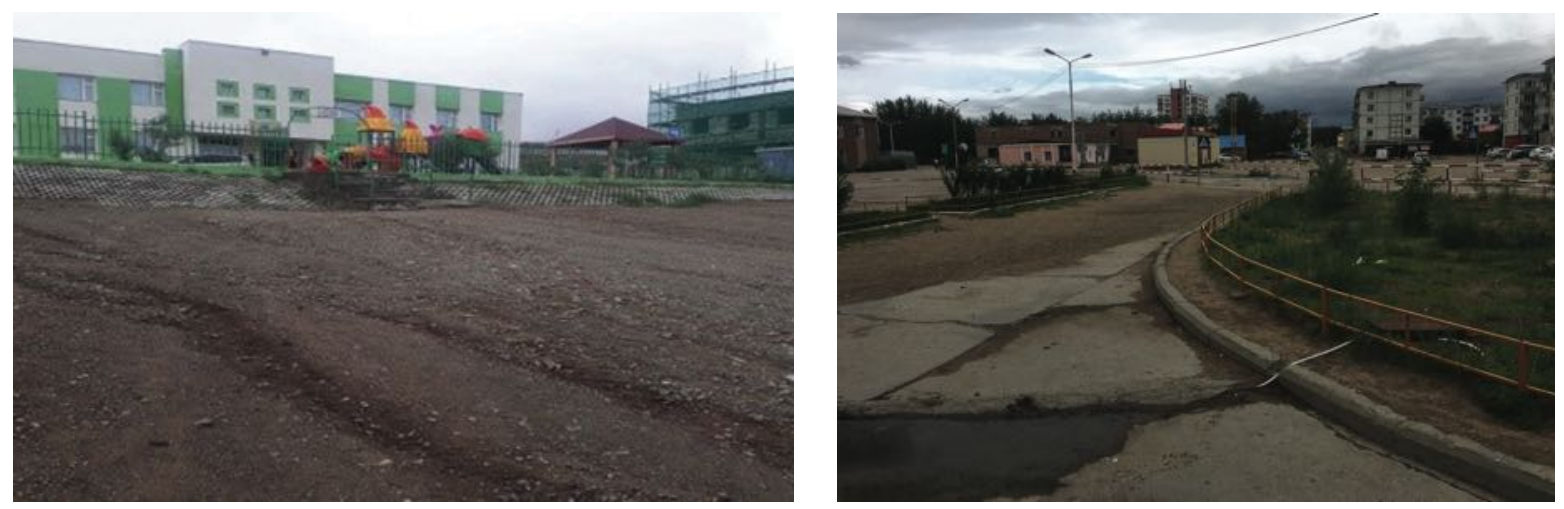

State of the road from the bus stop. Left photo shows Songino-Khairkhan Kindergarten no. 253; and on the right, Dornod aimag School no. 1 (photos from IRIM).

76. There are also major challenges for children with visual impairment in reaching schools and kindergartens from bus stops, as seen in the next photos.
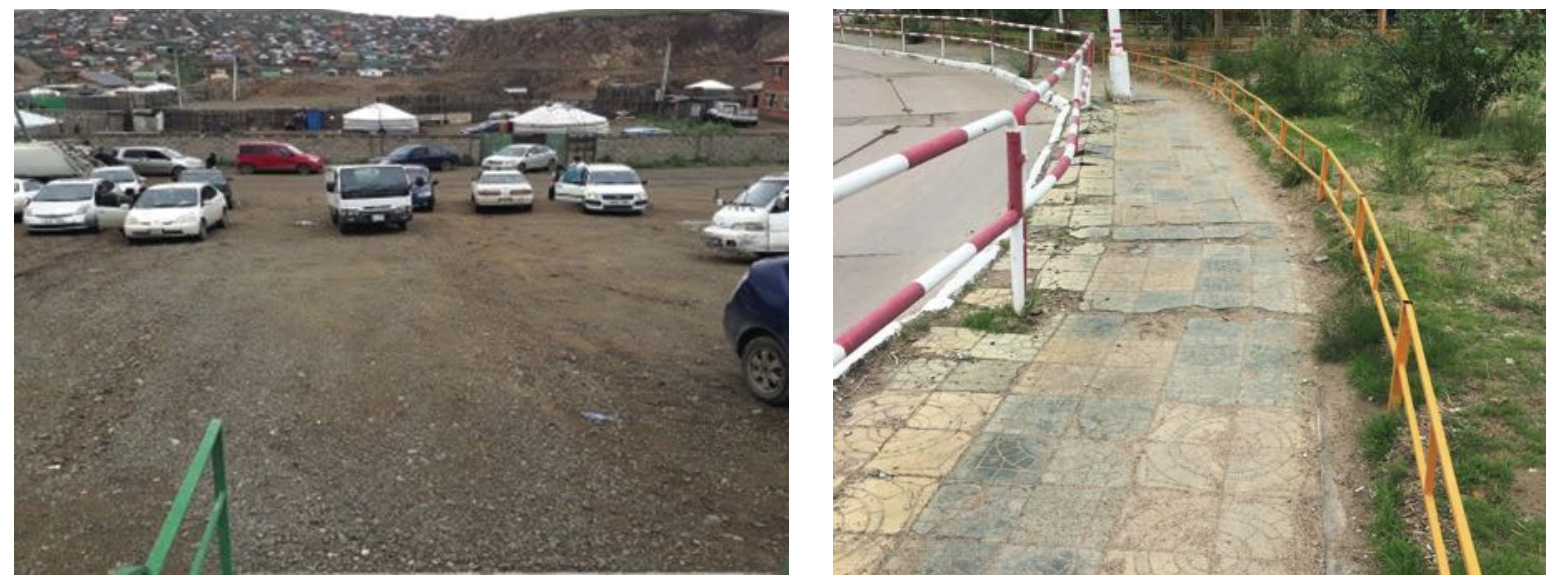

Lack of crosswalks and uneven surfaces. Left photo shows Songino-Khairkhan Kindergarten no. 253, which lacks a crosswalk accessible to people with visual impairment;. and on the right, the Dornod aimag School no. 1 has an uneven sidewalk surface (photos from IRIM).

77. School and kindergarten fence entrance's width, road accessibility, and handrail and guards to the main building entrances were unsatisfactory. The following photos show examples of schools that lack roads, handrails, and guards specified for wheelchair access, along with insufficient door width. 

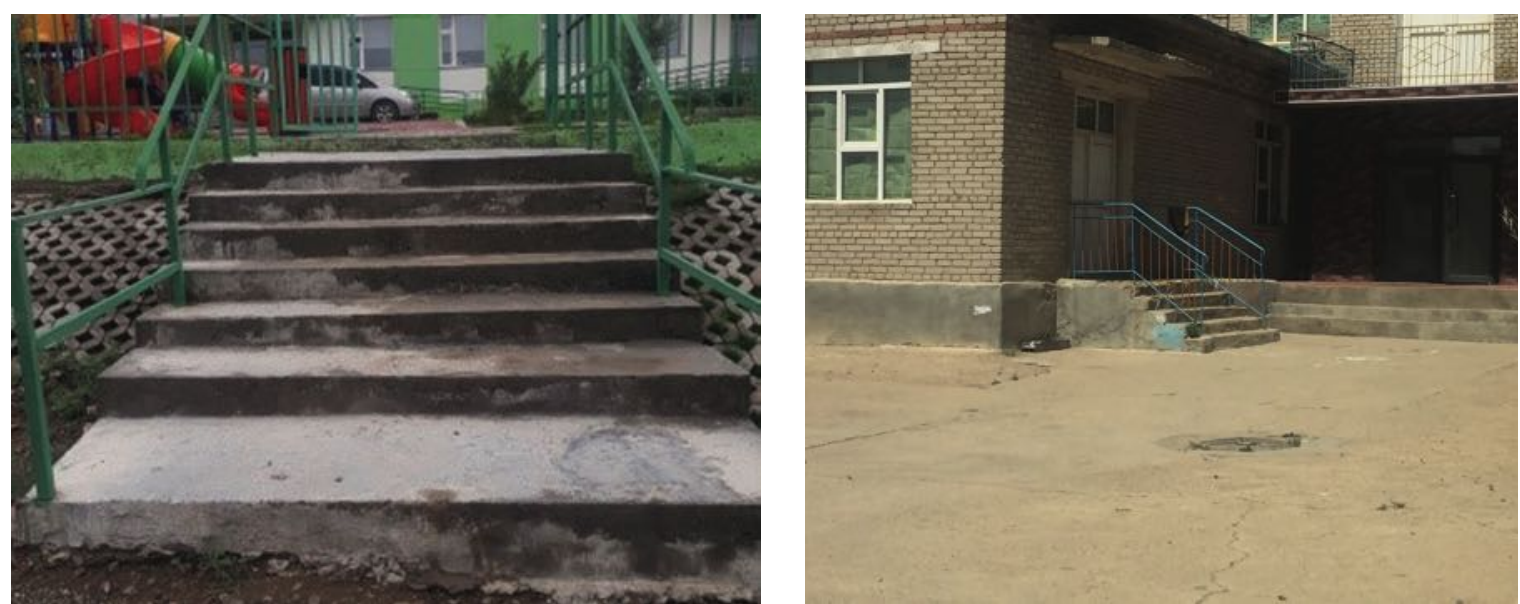

Inaccessible entrances. Left photo shows Songino-Khairkhan Kindergarten no. 253; and on the right, the Dornod aimag School no. 3 (photos by IRIM).

78. More than one-fourth of mothers or guardians of older children reported that their children have difficulties with the indoor school environment. Among the difficulties, $14.9 \%$ were associated with utilizing restrooms, $12.1 \%$ were linked to accessing the library, and $7.7 \%$ were related to staircases. Among mothers or guardians of younger children, 5.9\% found that the indoor environment of their kindergarten posed difficulties, with $5 \%$ related to using indoor staircases, and $3 \%$ associated with restroom accessibility. In total, $15 \%$ of mothers or guardians with older children and $5 \%$ of mothers or guardians with younger children reported that both the indoor and outdoor environments posed difficulties for their children.

\section{Figure 11: Difficulties with the Indoor Environments}

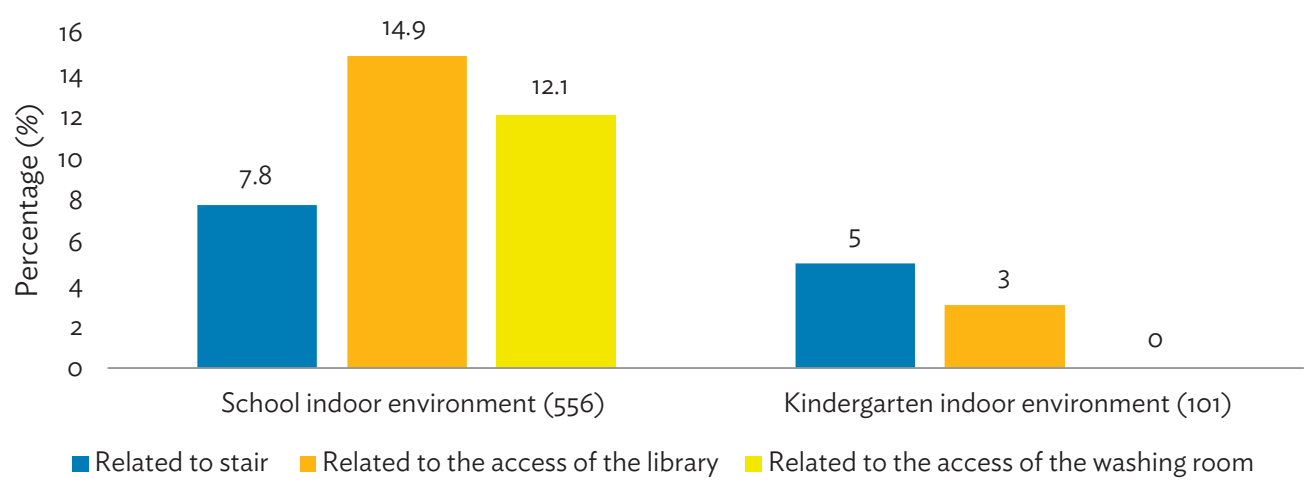

Source: IRIM. 2019. Support for Inclusive Education. Technical assistance consultant's report prepared for the Asian Development Bank. Manila.

79. Indoor environments were not sufficiently secure or accessible to allow children with disabilities to move safely and independently within the school and classrooms. The next photos depict several examples from a school that lacks single or double handrails and slip-proof mats on floors and stairs. Restrooms were impossible to use without assistance from teachers, staff, or peers. 

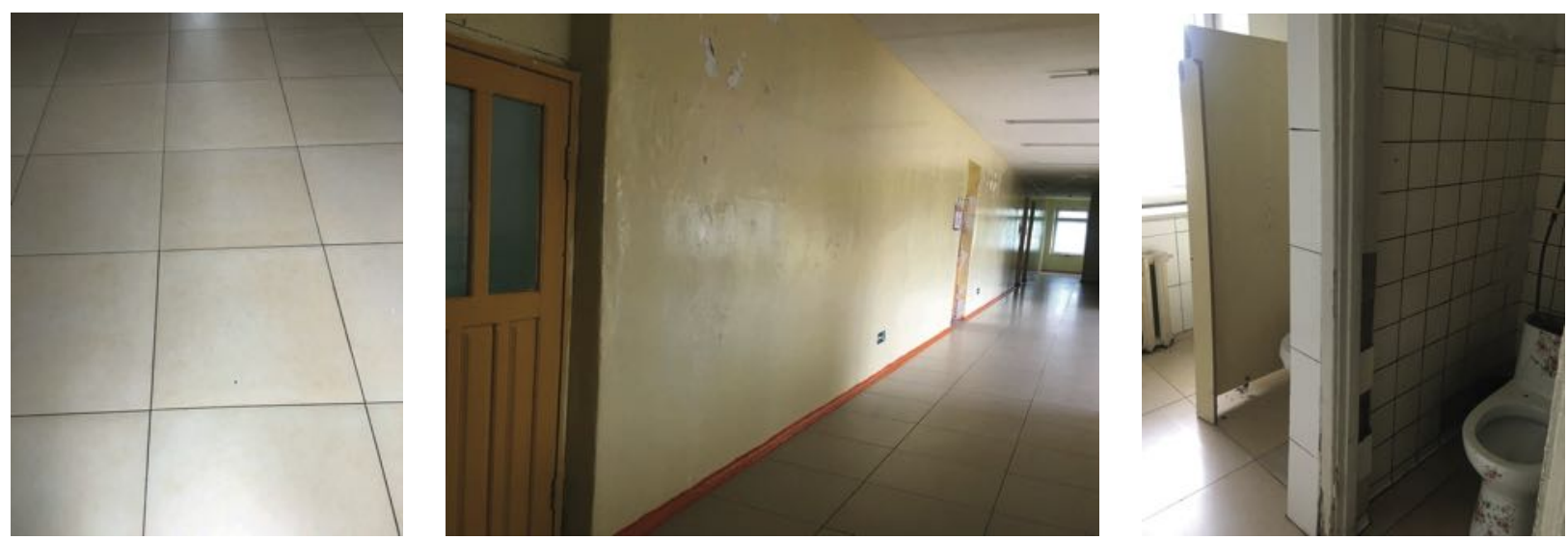

State of school and kindergarten indoor environments. The photos show different areas of Dornod aimag School no. 1 that are not sufficiently secure or accessible for children with disabilities (photos by IRIM).

80. Mothers and guardians reported several physical environment difficulties that indicate a need for improvement, most of which are problematic for all children, not just those with disabilities:

(i) overcrowded classrooms,

(ii) lack of school transport,

(iii) lack of wheelchair-accessible roads,

(iv) an outdoor-only restroom (Dornod aimag),

(v) overcrowded, small classrooms with an inefficient heating system (Khuvsgul aimag), and

(vi) insufficient textbooks and learning materials intended for children with disabilities.

81. Accessibility of the physical environment. Only $57 \%$ of caregivers of older children believe schools have enough textbooks, but $83 \%$ said their children fully use the learning materials. There are not enough psychological support spaces or professional psychological consultants: only $6 \%$ of caregivers noted the presence of a psychological support room that the children can use to calm down during challenging events, while only $3 \%$ reported the presence of teachers who can provide emotional support by addressing feelings and having a conversation with the child.

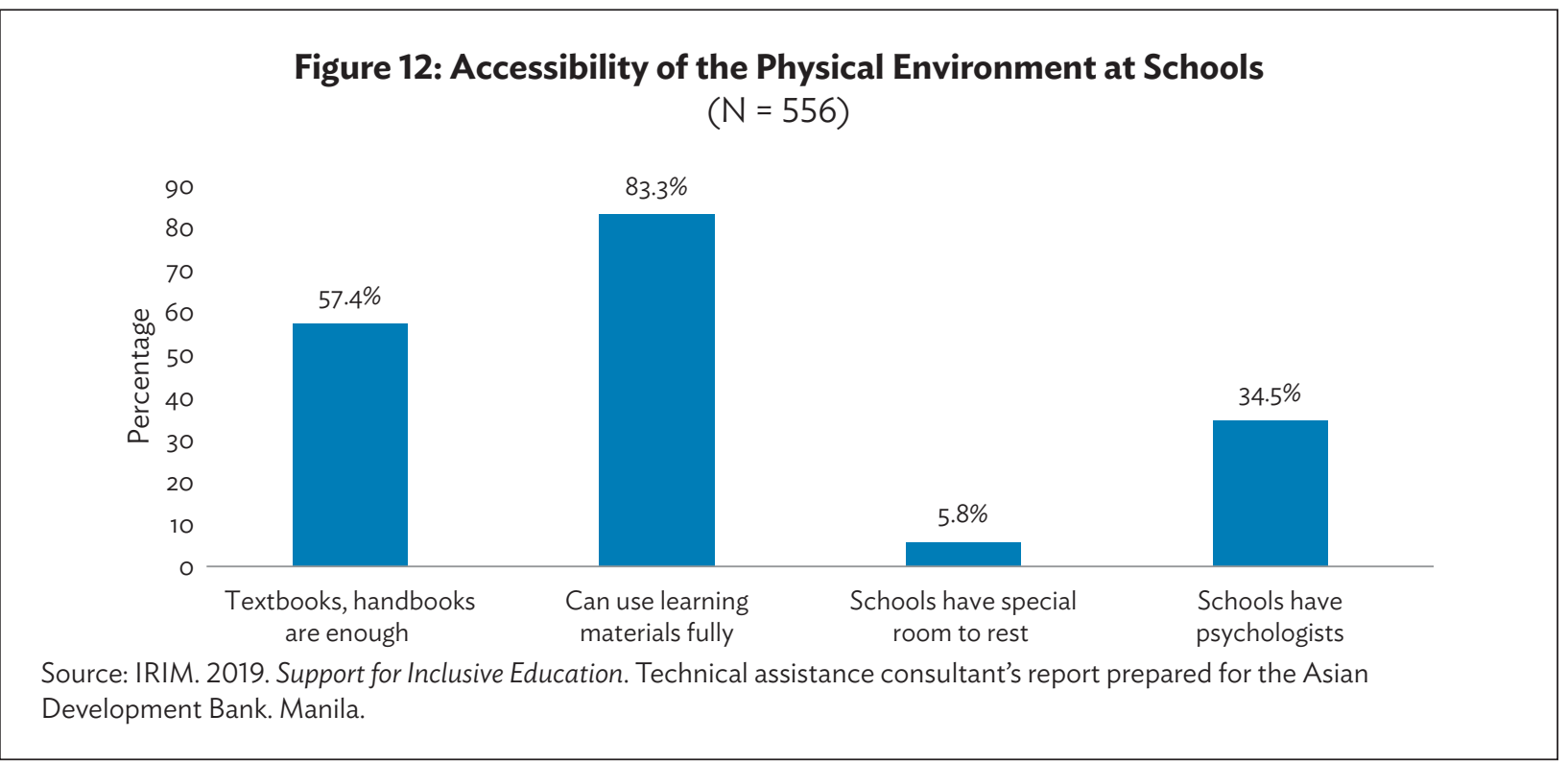


82. The supply of learning materials, books, and textbooks is also insufficient to meet the cognitive, intellectual, social, and behavioral needs of children with disabilities. One parent's views are in Box 3. There are also not enough professionals to meet the demand for support, including psychologists, language therapists, physiotherapists, sign language teachers, and others.

\section{Box 3: Support for Special Needs at School}

There is a lack of equipment and textbooks, and most importantly, there is no professional psychologist. Some of the most pressing difficulties that we [mother and son] are facing include insufficient textbooks, learning materials, equipment, and other things that should be available to visually impaired children. It would be better if he could play with toys that are based on his senses. There is a toy that can be played with using fingertips to develop touch perception. I have researched it, but it is not available here in my soum. Equipment and toys for children with sight difficulties are very much lacking.

Source: Interview with the mother of a visually impaired child, Dundgovi Province, 6 July 2019.

83. Projects to improve the physical environment. Relatively few schools improved their environment within the past year: only $17 \%$ of caregivers of older children stated that their schools made indoor or outdoor renovations intended for children with disabilities in the last year, despite approximately one-third of the respondents being asked by the schools for suggestions for renovations (Figure 13). Kindergartens appear to have made more attempts to improve the outdoor and indoor environment: $40 \%$ respondents with younger children reported that renovations were made to both indoor and outdoor facilities in the last year, with more than $30 \%$ reporting they were asked to share suggestions for renovations.

Figure 13: Activities to Improve the Accessibility of School and Kindergarten Environments as Reported by Parents

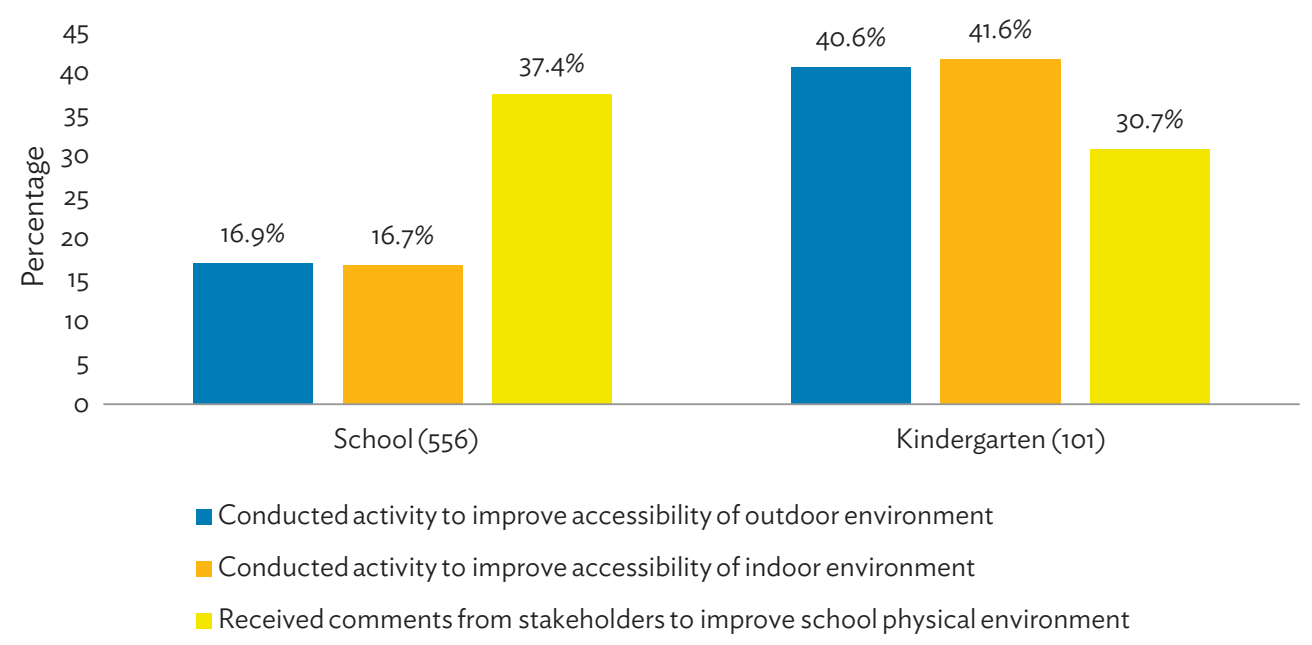

Source: IRIM. 2019. Support for Inclusive Education. Technical assistance consultant's report prepared for the Asian Development Bank. Manila. 
84. Half of the respondents with older children reported that the indoor and outdoor environments of schools are safe, while 38\% believe the surroundings are dangerous (Figure 14). On the other hand, when teachers were asked about the accessibility of their classrooms, $75 \%$ answered positively (Figure 15).

Figure 14: Parents' Views on the Safety of the Indoor and Outdoor Environments $(N=556)$

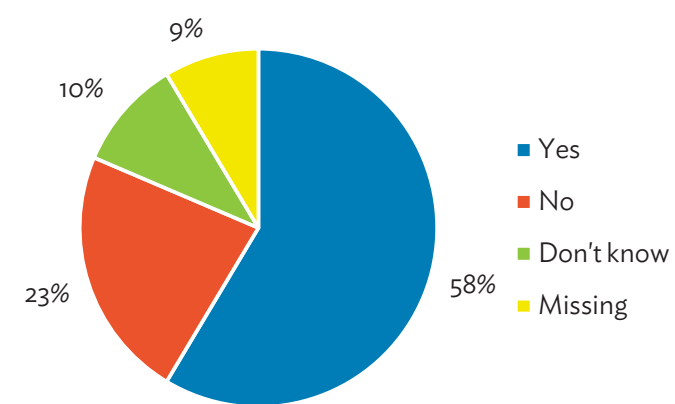

Source: IRIM. 2019. Support for Inclusive Education. Technical assistance consultant's report prepared for the Asian Development Bank. Manila.

Figure 15:Teachers' Views on the Accessibility of Classrooms

$(N=76)$

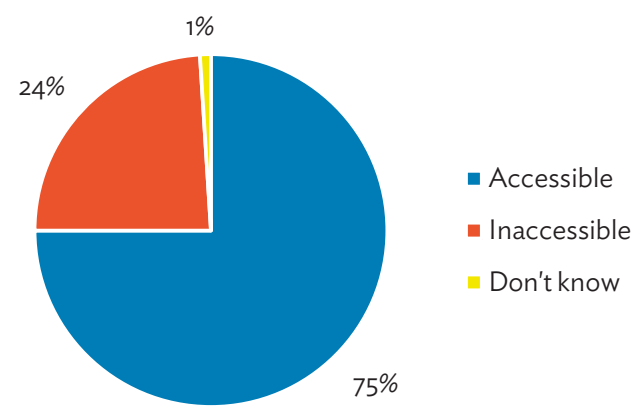

Source: IRIM. 2019. Support for Inclusive Education. Technical assistance consultant's report prepared for the Asian Development Bank. Manila.

85. To improve the quality of education for children with disabilities and to ensure an inclusive physical environment, the following protocols should be implemented in the development of school infrastructure and teaching and learning materials:

(i) safe, healthy, sanitary environments;

(ii) standard classroom sizes and enrollment;

(iii) improved and safe transport to and from schools;

(iv) increased availability of textbooks that meet the specific needs of children with disabilities, considering different types of functional difficulty;

(v) enhanced participation of children and parents in improving the inclusive physical learning environment;

(vi) improved and increased teaching materials, equipment, and support; and

(vii) enhanced accessibility of physical education spaces, playgrounds, and restrooms. 


\section{CONCLUSIONS AND RECOMMENDATIONS FOR STRENGTHENING INCLUSIVE EDUCATION IN MONGOLIA}

86. Based on a social model of disability, our study applied the child functioning module to screen Mongolian children with functional difficulties who are at risk of not getting an adequate education. The functional abilities are the basic abilities used in everyday life that can directly affect children's social inclusion, such as interacting with social, physical, economic, informational, and other barriers in the environment, and effectively prevent them from fully participating in education or community life. The survey found that $9.1 \%$ of the 9,555 children involved in the screening aged 2-17 from a total of 5,328 households had some form of functional difficulty.

87. The study constructed four Mongolian indicators of inclusion: inclusive cultures, policies, practices, and physical environments.

(i) Inclusive cultures. Recognizing children's special needs and diverse identities, establishing friendly environments, and implementing inclusive values in policy and practice were not sufficient among the selected kindergartens and schools. Children with physical difficulties including those related to seeing, hearing, walking, and speaking experienced greater negative impacts from the cultural environment in kindergarten. Meanwhile, schoolchildren faced cognitive and communication skills challenges including making friends, starting a conversation, learning, and remembering. Attitudes to respecting personal information and belongings among children had the most negative responses in the school cultural environment.

(ii) Inclusive policies. The share of children with disabilities enrolled in kindergarten was low, but relatively higher for school. However, neither the kindergartens nor the schools had the flexibility to organize, adapt, or support additional teaching for children's specific needs. The capacity of kindergartens and schools to cooperate with other professional organizations was generally inadequate to effectively work with children with functional difficulties.

(iii) Inclusive practices. Inclusive practices were found to be insufficient to promote an acceptance of diversity and to teach children how to respect others' differences. The activities of schools and kindergartens in this area were weak. The performance of agencies in providing additional activities to meet the different needs of children with special needs was weak. Inclusiveness in the kindergarten and school environments was insufficient and the lack of access to appropriate policy, culture, or physical environments did not have the potential to increase the educational opportunities for children with functional disabilities.

(iv) Inclusive physical environments. For children who have functional difficulties, the biggest challenge in the outdoor environment was related to using public transport to and from their school. On indoor environments of schools, the most common problem was the use of toilet facilities. The main difficulties encountered in classrooms were the inadequacy of training materials and special tools. 
88. Implementation of inclusive education policy is at an early stage, so it is not surprising that all key indicators of an inclusive educational environment in Mongolia were assessed as lacking, but it is important to note that policies and culture, in many domains, were assessed positively by parents. Only in the area of discrimination is there no real progress yet (as reported by parents). More work is needed in translating policies and cultures into good practice in the classroom. While Mongolia's policy and legal environment has seen considerable progress to support inclusive education, gaps include the financial and human resources needed to fully implement the regulations and procedures. There is also evidence of variation in the perceptions among various education sector stakeholders of the meaning and requirements of inclusive education. This creates a barrier for effective implementation of inclusive education cultures, policies, practices, and physical environments in Mongolia. A detailed matrix of specific recommendations based on the main findings is in Table 11. The recommendations are split into two categories: those for development partner programs and projects, and those for government policies and programs.

89. The survey results and recommendations presented here have informed the design of a new ADB grant to MECSS (the Ministry of Education and Science as of July 2020) to support inclusive education, built on the premise that children with disabilities have a right to benefit both academically and socio-emotionally from attending mainstream kindergartens and schools with their same-age peers. The $\$ 2$ million grant from the Japan Fund for Poverty Reduction, approved in July 2020, will aim to improve both access to and the quality of mainstream education for children with disabilities by improving accessibility features in selected schools and kindergartens; building capacity among teachers, managers, and local government officials to deliver inclusive education; and strengthening inclusive education support resources, community engagement, and policy. ${ }^{27}$ Many of the grant activities planned for the 4-year implementation period are based on specific recommendations presented here.

90. The project has strong pro-poor, socially inclusive, and gender-sensitive features. The direct beneficiaries will be children with disabilities and their families - especially women as primary caregiversbut inclusive education also brings significant benefits to the wider community. Many of the approaches required to improve education for children with disabilities, such as using formative assessment to gauge understanding and tailoring teaching to individual needs, are also important for improving learning for all students. Beyond this, the inclusion of children with disabilities in mainstream classrooms is also an opportunity to engage all children in discussions around inclusion and global citizenship more generally.

27 ADB. 2020. Mongolia: Support for Inclusive Education Project. Manila. 
Table 11: Matrix of Recommendations for Government and Development Partners

\begin{tabular}{|c|c|c|c|}
\hline \multirow[b]{2}{*}{ No. } & \multirow[b]{2}{*}{ FINDINGS } & \multicolumn{2}{|c|}{ RECOMMENDATIONS } \\
\hline & & $\begin{array}{l}\text { For Development Partner and Civil } \\
\text { Society Projects and Programs }\end{array}$ & $\begin{array}{c}\text { For Government Policy } \\
\text { and Programs }\end{array}$ \\
\hline & \multicolumn{3}{|l|}{ General } \\
\hline 1 & $\begin{array}{l}\text { Younger children ( } 2-5 \text { years) can } \\
\text { have a range of functional difficulties } \\
\text { and individual needs that can } \\
\text { sometimes be difficult to assess and } \\
\text { identify. }\end{array}$ & $\begin{array}{l}\text { - Study international assessment } \\
\text { methodologies for identifying the } \\
\text { specific needs of younger children } \\
\text { with functional difficulties. } \\
\text { - Pilot the school support team } \\
\text { in kindergartens to determine } \\
\text { the additional support required } \\
\text { for children with functional } \\
\text { difficulties. } \\
\text { Train kindergarten teachers to } \\
\text { improve their skills to better } \\
\text { work with younger children with } \\
\text { specific functional difficulties. }\end{array}$ & $\begin{array}{l}\text { Deliver training and mentoring to } \\
\text { build the capacity of the members of } \\
\text { the central and branch commissions } \\
\text { for health, education, and social } \\
\text { welfare. } \\
\text { - Implement regulations to add } \\
\text { resources to existing school and } \\
\text { kindergarten budgets to support } \\
\text { inclusive education. } \\
\text { - Build disability inclusion into } \\
\text { education and training (pre-service } \\
\text { and in-service) of preschool } \\
\text { teachers and teaching assistants. }\end{array}$ \\
\hline 2 & $\begin{array}{l}\text { For school-age children (6-17 } \\
\text { years), apart from easily identifiable } \\
\text { functional difficulties with seeing, } \\
\text { hearing, or mobility, "invisible" } \\
\text { functional disabilities including } \\
\text { cognitive difficulties and mental } \\
\text { health issues such as anxiety and } \\
\text { depression can also represent a } \\
\text { significant challenge to access quality } \\
\text { education. }\end{array}$ & $\begin{array}{l}\text { - Assess whether children with } \\
\text { functional difficulties are } \\
\text { adequately identified in the } \\
\text { Education Sector Information } \\
\text { System. } \\
\text { - Establish school support teams } \\
\text { to assess schoolchildren and to } \\
\text { develop and supervise individual } \\
\text { development plans. } \\
\text { - Organize a step-by-step program } \\
\text { to improve the capacity of } \\
\text { the school support team to } \\
\text { teach children with functional } \\
\text { difficulties. } \\
\text { - Support increased social } \\
\text { participation of children with } \\
\text { functional difficulties through } \\
\text { peer support and community } \\
\text { outreach programs. }\end{array}$ & $\begin{array}{l}\text { To better capture children with } \\
\text { functional difficulties in the } \\
\text { Education Sector Information } \\
\text { System, use the International } \\
\text { Classification of Functioning or at } \\
\text { least partially adapt it as part of } \\
\text { an educational needs assessment } \\
\text { method. } \\
\text { - This will need to also be } \\
\text { accompanied by training for } \\
\text { teachers and head teachers. Any } \\
\text { change in the system of assessment } \\
\text { for education purposes should be } \\
\text { aligned with the wider mechanisms } \\
\text { being used for disability assessment } \\
\text { in the health sector. A unified } \\
\text { system should be developed based } \\
\text { on the same set of concepts and } \\
\text { assessment framework. }\end{array}$ \\
\hline 3 & $\begin{array}{l}\text { There are gaps in access to assistive } \\
\text { devices and technology, } \\
\text { physiotherapy and occupational } \\
\text { therapy, and speech therapy. }\end{array}$ & $\begin{array}{l}\text { Support activities aimed at } \\
\text { providing psychological support, } \\
\text { speech therapy, physiotherapy, } \\
\text { and occupational therapy. } \\
\text { Provide assistive devices and } \\
\text { technology such as wheelchairs, } \\
\text { hearing aids, glasses, computer- } \\
\text { aided speech devices, and other } \\
\text { technology. }\end{array}$ & $\begin{array}{l}\text { - Coordinate with the health and } \\
\text { social welfare systems to enable } \\
\text { children's access to needed } \\
\text { services. } \\
\text { Empower social staff and school } \\
\text { doctors to provide psychological } \\
\text { support and counseling to } \\
\text { children. }\end{array}$ \\
\hline \multicolumn{4}{|c|}{ Creating inclusive cultures } \\
\hline 4 & $\begin{array}{l}\text { Children's special needs and diverse } \\
\text { identities are not always recognized, } \\
\text { some school environments are } \\
\text { not disability-friendly, and the } \\
\text { implementation of inclusive values } \\
\text { has gaps in policy and practice. } \\
\text { Parents are particularly unhappy } \\
\text { with the level of discrimination their } \\
\text { children experience. }\end{array}$ & $\begin{array}{l}\text { Introduce multidisciplinary } \\
\text { activities to showcase the range } \\
\text { of physical diversity (play games } \\
\text { showing diversity, promote } \\
\text { diversity messages using } \\
\text { animated films, cartoon theater, } \\
\text { finger dolls, etc.). }\end{array}$ & $\begin{array}{l}\text { Define the content of human } \\
\text { diversities and how they are } \\
\text { addressed, communicated, and } \\
\text { received in the textbooks of } \\
\text { kindergartens and school by their } \\
\text { age. }\end{array}$ \\
\hline
\end{tabular}


Table 11: continued

\begin{tabular}{|c|c|c|c|}
\hline \multirow[b]{2}{*}{ No. } & \multirow[b]{2}{*}{ FINDINGS } & \multicolumn{2}{|c|}{ RECOMMENDATIONS } \\
\hline & & $\begin{array}{l}\text { For Development Partner and Civil } \\
\text { Society Projects and Programs }\end{array}$ & $\begin{array}{c}\text { For Government Policy } \\
\text { and Programs }\end{array}$ \\
\hline & & $\begin{array}{l}\text { - Organize activities to enable } \\
\text { understanding of people's } \\
\text { differences related to cognitive, } \\
\text { abilities, communication, and } \\
\text { self-care. } \\
\text { - Share the understanding of primary } \\
\text { and secondary diversity with } \\
\text { teachers, and promote methods } \\
\text { for understanding the diversity of } \\
\text { children, to be delivered through } \\
\text { training. } \\
\text { - Organize events related to the } \\
\text { inclusive cultures and values in } \\
\text { the school environment, and } \\
\text { incorporate them into the annual } \\
\text { plan of kindergartens and schools. } \\
\text { Work with multi-stakeholder } \\
\text { groups to build an inclusive } \\
\text { culture of equality in the school } \\
\text { environment. } \\
\text { Support groups of parents of children } \\
\text { with disabilities to cooperate with the } \\
\text { school support team. } \\
\text { - Organize training for parents of } \\
\text { children with disabilities on how to } \\
\text { support their children. } \\
\text { Organize awareness-raising } \\
\text { activities in schools for parents } \\
\text { of children without functional } \\
\text { difficulties about the value of } \\
\text { abganize events to share information } \\
\text { about inclusive education. } \\
\text { - }\end{array}$ & $\begin{array}{l}\text { Train and encourage school } \\
\text { principals, social workers, } \\
\text { and administrators to include } \\
\text { humanitarian issues in the school } \\
\text { curriculum. } \\
\text { - Conduct a training course on } \\
\text { humanitarian, positive, and } \\
\text { helpful attitudes and train school } \\
\text { principals, social workers, and } \\
\text { administrators. } \\
\text { - Include a basic understanding of } \\
\text { the content of inclusive education } \\
\text { in the civic education. } \\
\text { - Support advocacy on the diversity } \\
\text { in functioning for parents. } \\
\text { - Support activities to increase } \\
\text { parental involvement in school } \\
\text { activities, including fathers. }\end{array}$ \\
\hline 5 & $\begin{array}{l}\text { More children with disabilities } \\
\text { experience negative impacts of the } \\
\text { culture environment at kindergarten. }\end{array}$ & $\begin{array}{l}\text { Organize training on how to } \\
\text { work with children with physical } \\
\text { disabilities (e.g., seeing, hearing, } \\
\text { walking, and communication } \\
\text { difficulties) for kindergarten } \\
\text { teachers. }\end{array}$ & $\begin{array}{l}\text { - Improve the content of teacher } \\
\text { training programs on functional } \\
\text { difficulties in the Institute } \\
\text { of Teachers' Professional } \\
\text { Development curriculum for } \\
\text { kindergarten teachers. }\end{array}$ \\
\hline 6 & $\begin{array}{l}\text { Children who have difficulties with } \\
\text { cognitive and communication skills, } \\
\text { such as friendship, communication, } \\
\text { and learning, feel the negative impact } \\
\text { of the cultural environment. }\end{array}$ & $\begin{array}{l}\text { Organize training for school } \\
\text { teachers to work with children } \\
\text { with functional difficulties in } \\
\text { communication, self-care, adapting } \\
\text { to change, remembering, making } \\
\text { friends, and learning. }\end{array}$ & \\
\hline 7 & $\begin{array}{l}\text { In the school environment, there is } \\
\text { discrimination against children with } \\
\text { disabilities. }\end{array}$ & $\begin{array}{l}\text { Support initiatives based on } \\
\text { childrens' participation and } \\
\text { organize outreach campaigns that } \\
\text { aim at creating understanding } \\
\text { among students and their parents } \\
\text { about rights and human dignity. }\end{array}$ & $\begin{array}{l}\text { - Include and reinforce provisions } \\
\text { including the content of inclusive } \\
\text { education in the various legal and } \\
\text { policy documents, such as codes of } \\
\text { conduct, teachers' job descriptions, } \\
\text { and the School Code of Conduct. }\end{array}$ \\
\hline
\end{tabular}


Table 11: continued

\begin{tabular}{|c|c|c|c|}
\hline \multirow[b]{2}{*}{ No. } & \multirow[b]{2}{*}{ FINDINGS } & \multicolumn{2}{|c|}{ RECOMMENDATIONS } \\
\hline & & $\begin{array}{l}\text { For Development Partner and Civil } \\
\text { Society Projects and Programs }\end{array}$ & $\begin{array}{c}\text { For Government Policy } \\
\text { and Programs }\end{array}$ \\
\hline \multirow[t]{2}{*}{8} & $\begin{array}{l}\text { Insufficient teacher capacity to cope } \\
\text { with special needs in the classroom. }\end{array}$ & $\begin{array}{l}\text { Improve the methodology for } \\
\text { identifying specific needs of } \\
\text { children with disabilities, share } \\
\text { experiences, and organize training } \\
\text { and events. }\end{array}$ & $\begin{array}{l}\text { - Include inclusive education } \\
\text { subjects in the mandatory subjects } \\
\text { of all universities, thereby preparing } \\
\text { and equipping future teachers. } \\
\text { - Allocate resources to support } \\
\text { teachers in the classroom } \\
\text { (materials, teaching assistants, etc.). }\end{array}$ \\
\hline & \multicolumn{3}{|l|}{ Producing inclusive policies } \\
\hline \multirow[t]{2}{*}{9} & $\begin{array}{l}\text { Legal documents on inclusive } \\
\text { education have been developed in } \\
\text { stages, but the understanding of the } \\
\text { concepts differ among professionals, } \\
\text { teachers, and parents. }\end{array}$ & $\begin{array}{l}\text { Organize outreach events } \\
\text { to inform professionals, } \\
\text { teachers, parents, and the } \\
\text { wider community about the } \\
\text { legal framework that supports } \\
\text { inclusive education in schools. } \\
\text { - Communication actions should } \\
\text { always involve disabled people's } \\
\text { organizations. }\end{array}$ & $\begin{array}{l}\text { - Include objective indicators } \\
\text { that reflect the inclusion of all } \\
\text { children in the catchment area } \\
\text { in the school strategy and annual } \\
\text { plan. } \\
\text { - Introduce the inclusive purpose, } \\
\text { indicators, and implementation } \\
\text { steps in the school annual plans } \\
\text { and to teachers and parents at } \\
\text { the beginning of the school year. } \\
\text { Hire more teachers, managers, } \\
\text { head teachers, and support staff } \\
\text { with disabilities. }\end{array}$ \\
\hline & \multicolumn{3}{|l|}{ Evolving inclusive practices } \\
\hline 10 & $\begin{array}{l}\text { Neither kindergartens nor schools } \\
\text { have the flexibility to organize, } \\
\text { coordinate, and provide additional } \\
\text { support for the specific needs of } \\
\text { children with functional difficulties. }\end{array}$ & $\begin{array}{l}\text { - Build the school support teams' } \\
\text { capacity to develop, implement, } \\
\text { and assess individual education } \\
\text { plans. } \\
\text { - Create a mechanism for sharing } \\
\text { teachers' capacity to develop, } \\
\text { implement, and evaluate } \\
\text { individual education plans of } \\
\text { children's functional difficulties, } \\
\text { with other teachers. } \\
\text { Establish a mechanism for } \\
\text { obtaining professional and } \\
\text { methodological assistance from } \\
\text { special schools for the purpose of } \\
\text { evaluating the ability of a child and } \\
\text { to develop individual education } \\
\text { plans within the target schools. }\end{array}$ & $\begin{array}{l}\text { Provide detailed guidance on } \\
\text { how to design, implement, and } \\
\text { evaluate individual education } \\
\text { plans. } \\
\text { - Provide resources to support } \\
\text { inclusion in the classroom } \\
\text { (personal assistants, teaching } \\
\text { assistants, materials, and } \\
\text { equipment). } \\
\text { Ensure that all children have the } \\
\text { assistive devices and technology } \\
\text { they need to be able to maximize } \\
\text { their engagement in the } \\
\text { classroom. }\end{array}$ \\
\hline 11 & $\begin{array}{l}\text { Intergovernment cooperation and } \\
\text { interagency support are insufficient. }\end{array}$ & $\begin{array}{l}\text { Support the establishment } \\
\text { of school enrollment support } \\
\text { councils in accordance with the } \\
\text { November } 2018 \text { Joint Ministerial } \\
\text { Order on Comprehensive Support } \\
\text { to Children with Disabilities } \\
\text { (November 2018) of the MLSP, } \\
\text { MECSS, and the Ministry of } \\
\text { Health. } \\
\text { Promote initiatives to strengthen } \\
\text { the school enrollment councils } \\
\text { and school support teams. }\end{array}$ & $\begin{array}{l}\text { Include information on school } \\
\text { dropout rates at the bagh and } \\
\text { khoroo schools using the School } \\
\text { Enrollment Support Council, } \\
\text { and add one classification to } \\
\text { the system that registers this } \\
\text { information to the education } \\
\text { management information } \\
\text { system. }\end{array}$ \\
\hline
\end{tabular}


Table 11: continued

\begin{tabular}{|c|c|c|c|}
\hline \multirow[b]{2}{*}{ No. } & \multirow[b]{2}{*}{ FINDINGS } & \multicolumn{2}{|c|}{ RECOMMENDATIONS } \\
\hline & & $\begin{array}{l}\text { For Development Partner and Civil } \\
\text { Society Projects and Programs }\end{array}$ & $\begin{array}{c}\text { For Government Policy } \\
\text { and Programs }\end{array}$ \\
\hline & \multicolumn{3}{|c|}{ Building inclusive physical environments } \\
\hline 12 & $\begin{array}{l}\text { For children with functional } \\
\text { difficulties, the biggest challenge in } \\
\text { outdoor environment was related to } \\
\text { using public transport to and from } \\
\text { the school. }\end{array}$ & $\begin{array}{l}\text { Test and provide transport } \\
\text { support teams based on } \\
\text { community participation, } \\
\text { including disabled people's } \\
\text { organizations and parents } \\
\text { of children with functional } \\
\text { difficulties. }\end{array}$ & $\begin{array}{l}\text { - Include programs to improve } \\
\text { access to schools in annual work } \\
\text { plans and budgets. } \\
\text { - Increase the availability of local } \\
\text { school buses to areas with poor } \\
\text { access to public transport. } \\
\text { - Coordinate with local } \\
\text { governments on improving roads } \\
\text { and pavements leading to schools } \\
\text { and kindergartens. }\end{array}$ \\
\hline 13 & $\begin{array}{l}\text { The most common problem } \\
\text { with indoor environments is the } \\
\text { accessibility of restrooms. }\end{array}$ & $\begin{array}{l}\text { Support improved accessibility of } \\
\text { separate toilets for boys and girls } \\
\text { in schools and kindergartens in } \\
\text { accordance with universal design } \\
\text { standards. }\end{array}$ & $\begin{array}{l}\text { Ensure the inclusion of separate } \\
\text { and accessible sanitation facilities } \\
\text { in the construction guidelines of } \\
\text { general education schools. } \\
\text { - Ensure mechanisms for } \\
\text { monitoring compliance with } \\
\text { construction standards and } \\
\text { guidelines. }\end{array}$ \\
\hline 14 & $\begin{array}{l}\text { The main difficulties encountered in } \\
\text { the classroom are the inadequacy of } \\
\text { training materials and special tools. }\end{array}$ & $\begin{array}{l}\text { Provide teaching and learning } \\
\text { materials for teachers who work } \\
\text { with children with functional } \\
\text { difficulties, and train teachers on } \\
\text { how to use them. } \\
\text { - Provide tools for diversity training } \\
\text { and awareness-raising exercises- } \\
\text { for example, toys and tools to } \\
\text { demonstrate human diversity in } \\
\text { kindergarten, or diversity-learning } \\
\text { materials for schools. }\end{array}$ & $\begin{array}{l}\text { - Amend guidelines on inclusive } \\
\text { education to include an appendix } \\
\text { of recommended and suitable } \\
\text { teaching and learning materials } \\
\text { and tools for diversity training and } \\
\text { awareness raising. }\end{array}$ \\
\hline
\end{tabular}

MECSS = Ministry of Education, Culture, Science and Sports, MLSP = Ministry of Labor and Social Protection.

Source: Asian Development Bank. 


\section{REFERENCES}

ADB. 2017. Mongolia: Ensuring Inclusiveness and Service Delivery for Persons with Disabilities Project. Manila

ADB. 2019a. Integrating Persons with Disabilities into Mongolia's Society. Observations and Suggestions 2019-02. Manila.

ADB. 2019b. Living with Disability in Mongolia: Progress Toward Inclusion. Manila.

ADB. 2019c. Mongolia's Social Welfare System: Expenditure Allocation and Beneficiary Profile. Consultant's report. Manila (TA 8845-MON).

ADB. 2020. Mongolia: Support for Inclusive Education Project. Manila.

Booth, T. and M. Ainscow. 2002. Index for Inclusion: Developing Learning and Participation in Schools. United Kingdom: Center for Studies on Inclusive Education.

Cologon, K. 2013. Inclusion in Education. Towards Equality for Students with Disability. Issues Paper. Children with Disabilities. Victoria.

Education Commission. 2017. The Learning Generation. New York: The Education Commission.

Government of Mongolia. 2017. National Program for the Rights, Participation, and Protection of Persons with Disabilities, 2018-2022. Ulaanbaatar.

International Research Institute of Mongolia (IRIM). 2019. Support for Inclusive Education. Technical assistance consultant's report prepared for the Asian Development Bank under TA 9216-MON Sustaining Access to and Quality of Education during Economic Difficulties. Manila.

Kulbir Singh, R. and O. Abu Alghaib. 2019. Every Learner Matters: Unpacking the Learning Crisis for Children With Disabilities. Washington, DC: World Bank Group.

Male, C. and Q. Wodon. 2017. The Price of Exclusion: Disability and Education-Disability Gaps in Educational Attainment and Literacy. Washington DC: Global Partnership for Education and The World Bank.

National Commission for Lifelong Education (NCLE). 2019. Screening School Aged Children Out of the School. NCLE Survey Report. Ulaanbaatar.

National Statistical Office (NSO). 2020. Household Socio-economic Survey 2018. Ulaanbaatar.

Save the Children. 2016. Inclusive Education: What, Why, and How-A Handbook for Program Implementers. Stockholm.

Save the Children. 2018. Needs Assessment for Promoting Inclusive Education for Every Last Child in Mongolia. Ulaanbaatar: International Research Institute of Mongolia. 
United Nations. 2016. Committee on the Rights of Persons with Disabilities General Comment No. 4 (2016) on the Right to Inclusive Education. CPRD/C/GC 4. Geneva.

United Nations Educational, Scientific and Cultural Organization. 2008. Inclusive Education: The Way of the Future. Final Report of the International Conference on Education, 48th Session, 25-28 November 2008. Geneva.

UNICEF. 2016. UNICEF Mongolia Country Programme Document 2017-2021. Ulaanbaatar.

United Nations Children's Fund (UNICEF). 2016a. Child Functioning Module Questionnaires. New York.

UNICEF. 2016b. UNICEF Mongolia Country Programme Strategy Note. Ulaanbaatar.

UNICEF and NSO. 2018. Mongolia: Multiple Indicator Cluster Survey 2018. Ulaanbaatar.

World Health Organization and World Bank. 2011. World Report on Disability. Malta. 


\section{Promoting Inclusive Education in Mongolia}

Children with disabilities suffer disproportionately from the learning crisis. The global commitment to inclusive education is captured in Sustainable Development Goal 4-ensuring inclusive and equitable education and promoting lifelong learning opportunities for all. This paper explores inclusive education for children with disabilities in Mongolia's mainstream education system, based on a 2019 survey of more than 5,000 households, interviews with stakeholders, and visits to schools and kindergartens in four provinces and one district of the capital city. Mongolia has developed a strong legal and policy framework for inclusive education aligned with international best practice, but implementation and capacity are lagging. The conclusion presents recommendations for government and education sector development partners.

\section{About the Asian Development Bank}

ADB is committed to achieving a prosperous, inclusive, resilient, and sustainable Asia and the Pacific, while sustaining its efforts to eradicate extreme poverty. Established in 1966, it is owned by 68 members -49 from the region. Its main instruments for helping its developing member countries are policy dialogue, loans, equity investments, guarantees, grants, and technical assistance. 